\title{
Antialgal activity of poly(2- (dimethylamino)ethyl methacrylate) (PDMAEMA) brushes against the marine alga Ulva
}

Wetra Yandi, Sophie Mieszkin, Maureen E. Callow, James A. Callow, John A. Finlay, Bo Liedberg and Thomas Ederth

\section{Journal Article}

\section{Tweet}

N.B.: When citing this work, cite the original article.

This is an electronic version of an article published in:

Wetra Yandi, Sophie Mieszkin, Maureen E. Callow, James A. Callow, John A. Finlay, Bo Liedberg and Thomas Ederth, Antialgal activity of poly(2-(dimethylamino)ethyl methacrylate) (PDMAEMA) brushes against the marine alga Ulva, Biofouling (Print), 2017. 33(2), pp.169183.

Biofouling (Print) is available online at informaworldTM:

http://dx.doi.org/10.1080/08927014.2017.1281409

Copyright: Taylor \& Francis: STM, Behavioural Science and Public Health Titles http://www.tandf.co.uk/journals/default.asp

Postprint available at: Linköping University Electronic Press

http://urn.kb.se/resolve?urn=urn:nbn:se:liu:diva-136184 


\section{Antialgal activity of poly(2-(dimethylamino)ethyl methacrylate) (PDMAEMA) brushes against the marine alga Ulva}

Wetra Yandi $^{\mathrm{a},}$, Sophie Mieszkin ${ }^{\mathrm{b}, 1,2}$, Maureen E. Callow ${ }^{\mathrm{b}}$, James A. Callow ${ }^{\mathrm{b}}$, John A. Finlay $^{\mathrm{b}, 3}$, Bo Liedberg ${ }^{\mathrm{a}, \mathrm{c}}$, Thomas Ederth ${ }^{\mathrm{a}, *}$

${ }^{a}$ Division of Molecular Physics, IFM, Linköping University, 58183 Linköping, Sweden

b School of Biosciences, University of Birmingham, UK

${ }^{\mathrm{c}}$ Centre for Biomimetic Sensor Science, School of Materials Science and Engineering, Nanyang Technological University, Singapore

${ }^{1}$ Present address: UMR 1136 Interactions Arbres/Microorganismes, Université de Lorraine, Vandoeuvre-lès-Nancy, France

2 Present address: UMR 1136 Interactions Arbres/Microorganismes, Laboratoire d'Excellence ARBRE, Institut National de la Recherche Agronomique, INRA-Nancy, Champenoux, France

${ }^{3}$ Present address: School of Marine Science and Technology, Newcastle University, Newcastle NE1 7RU, UK

*Author to whom correspondence should be addressed. E-mail: ted@ifm.liu.se.

Published in:

Biofouling, 33(2), 169-183 (2017). DOI: 10.1080/08927014.2017.1281409. 


\begin{abstract}
Marine biofouling has detrimental effects on the environment and economy, and current antifouling coatings research is aimed at environmentally benign, non-toxic materials. We explore the possibility of contact-active coatings, by considering the antialgal activity of cationic poly(2-(dimethylamino)ethyl methacrylate) (PDMAEMA) brushes. The antialgal activity was investigated via zoospore settlement and sporeling growth assays of the marine algae Ulva linza and U. lactuca. The assay results for PDMAEMA brushes were compared to those for anionic and neutral surfaces. We found that only PDMAEMA can disrupt zoospores that come into contact with it, and that it also inhibits the subsequent growth of normally settled spores. Based on the spore membrane properties, and characterization of the PDMAEMA brushes over a wide $\mathrm{pH}$ range, we hypothesize that the algicidal mechanisms are similar to the bactericidal mechanisms of cationic polymers, and foresee that further development could lead to successful contact-active antialgal coatings.
\end{abstract}

Keywords: poly(2-(dimethylamino)ethyl methacrylate), polymer brushes, antialgal, Ulva, spores settlement assay, sporeling growth. 


\section{Introduction}

Biofouling is a considerable problem in marine industries. The accumulation of fouling organisms on the surfaces of ships, heat exchangers, water intakes, oceanographic instruments, and aquaculture systems leads to serious economic and environmental penalties. Copper and organotin biocides have been effective in combating biofouling, but their uses are being limited or banned due to environmental concerns (Cheyne 2010, Thomas \& Brooks 2010). Adhesion-resistant, fouling-release and contact-active coatings are some of the strategies that are used to replace biocidal materials, and to provide environmentally benign antifouling coatings. The design of effective coatings is challenging, and despite decades of research on marine biofouling, settlement cues and attachment mechanisms are poorly understood for many major fouling species. Many factors influence the settlement and adhesion of organisms, and the large variety of strategies and mechanisms among fouling organisms exacerbates the problem.

Green algae of the genus Ulva comprise a group of major fouling organisms that are widely spread along coasts around the world. Adult plants produce vast amounts of microscopic motile swimming zoospores that disperse and strive to find a suitable place to settle (Callow \& Callow 2002). Ulva spores do not have a cell wall, but expose a naked lipoprotein membrane, which is negatively charged. (Rosenhahn et al. 2009) This implies that spores might interact differently with anionic and cationic surfaces, and it has indeed been reported that spores of $U$. linza have a strong affinity for cationic surfaces, which can interfere with the normal settlement process in a way that has not been observed with anionic surfaces (Ederth et al. 2008, Ederth et al. 2009, Rosenhahn et al. 2009, Yandi et al. 2016). This suggests that the spores might be susceptible to deliberate interference by cationic materials.

Cationic polymers have emerged as promising candidates for the development of new antimicrobial agents (Muñoz-Bonilla \& Fernández-García 2012). For example chitosan (Li et al. 2011), poly(diallyldimethylammonium chloride) (Melo et al. 2010), derivatives of polynorbornene, (Ilker et al. 2004) poly(vinyl-N-hexylpyridium) (Tiller et al. 2001), and poly(2-(dimethyl amino)ethyl methacrylate) (PDMAEMA) (Lee et al. 2004b, Liu et al. 2007, Rawlinson et al. 2010), which are natural and synthetic cationic 
polymers, are under scrutiny. PDMAEMA is a $\mathrm{pH}$ - and temperature-sensitive material due to the presence of hydrophilic amino groups, and the hydrophobic segments at the end of the side chains (Liu et al. 2007). In a highly acidic environment $(\mathrm{pH}<5)$ PDMAEMA is hydrophilic and fully ionized by protonation of the tertiary amine, and it interacts strongly with surrounding water molecules. Ion-dipole interactions between ammonium ions and polar water molecules create strong solvation or hydration shells. However, as the $\mathrm{pH}$ increases, this interaction is weakened due to decreasing protonation of amine groups, and the hydrophobic properties of the methylated amines become more pronounced, resulting in amphiphilic behavior. It appears that this interaction might increase the antimicrobial activity; research on amphiphilic polynorbornene derivatives with variations in the hydrophobic moieties show that the introduction of hydrophobic groups on cationic polymers leads to an increase in antibacterial and hemolytic activity, which is dependent on the size of the hydrophobic group (Ilker et al. 2004).

Polymer brushes allow for considerable flexibility in preparing model interfaces and for altering interfacial properties via variations in monomer chemistry, grafting density, and coating thickness, and are used to vary and control interfacial properties in many disciplines, including the biomedical field in general (Galvin \& Genzer 2012, Krishnamoorthy et al. 2014), and also in antifouling applications (Higaki et al. 2016, Yang et al. 2014). The role of surface charge in antifouling coatings is of relevance also for other reasons than preparing antimicrobial coatings. Most surfaces, including nominally neutral surfaces, become charged upon immersion in water, and electrostatic interactions are important in the recruitment and adhesion of biomacromolecules and microorganisms. Hence, the role of surface charge for marine antifouling properties of polymer brushes has been investigated (Yandi et al. 2016, Yang et al. 2012). Further, there is a strong current interest in the antifouling properties of zwitterionic materials, and especially in controlling antifouling properties via the strong hydration in zwitterionic brushes (Chen \& Jiang 2008) Guo et al. 2015). Although brushes of PDMAEMA (Keely et al. 2007, Rawlinson et al. 2010) and its quaternized derivatives (Huang et al. 2007, Lee et al. 2004a, Roy et al. 2008) have been exploited for antimicrobial purposes, the potential application of PDMAEMA as an antialgal agent has not yet been studied. Research on the antialgal activity of cationic polymers in general is sparse, and dominated by tests using microalgae (Subramanyam et 
al. 2009) and often with negative results (Kugel et al. 2009, Park et al. 2010), with a notable exception by Krishnan et al demonstrating that pyridinium polymers with fluorinated sidechains inhibit the growth of sporelings of $U$. linza (Krishnan et al. 2005).

In this work, we investigate the interactions of zoospores of the marine algae $U$. linza and $U$. lactuca with the cationic PDMAEMA polymer, in order to investigate any antialgal effect of the polymer on either the settlement and germination of the zoospores or the subsequent growth of sporelings (young plantlets). Results are compared to those obtained on hydrophobic, methyl-terminated self-assembled monolayers (SAMs), which are known to induce high settlement of spores (Callow et al. 2000, Finlay et al. 2002), onto oligo(ethylene glycol)-terminated SAMs, which have been found to be very resistant to spore settlement (Schilp et al. 2007), and onto glass slides, which are negatively charged, and widely used as standard substrates for algal settlement and sporeling growth assays. Zoospores of the two species $U$. linza and $U$. lactuca have been found to perform qualitatively similarly in previous biofouling assays, both by us (unpublished data) and others (Yan et al. 2012). A secondary aim of this study was to compare the outcome of assays using these two species, that were also collected at different locations.

\section{Materials and Methods}

Materials. 2-(dimethylamino)ethyl methacrylate (DMAEMA), 1-octadecanethiol, copper (I) bromide (99.999\%), and 2,2-bipyridine (BPY, 99\%) were purchased from SigmaAldrich Sweden AB. $\alpha$-bromoisobutyrate-11-undecanethiol for the initiator SAM, and 1mercaptoundecyl oligo ethylene glycol (HS-C11-EG6), were purchased from ProChimia Surfaces, Poland. Spore settlement and sporeling growth assays were carried out using glass microscope slides (cleanroom-cleaned Nexterion B, $26 \times 76 \times 1 \mathrm{~mm}^{3}$, Schott AG, Germany) coated on one side with polymer. Phosphate-buffered saline (PBS) was prepared by dissolving PBS tablets (Sigma-Aldrich Sweden AB) into $200 \mathrm{~mL}$ of Milli-Q (MQ) water (>18.2 M $\Omega \mathrm{cm}$, Millipore) and adjusting to $\mathrm{pH}$ 7.4. Artificial seawater (ASW) was prepared by dissolving $24.5 \mathrm{~g}$ of sodium chloride, $4.1 \mathrm{~g}$ of sodium sulfate, $11.1 \mathrm{~g}$ of magnesium chloride hexahydrate, $1.5 \mathrm{~g}$ of calcium chloride dihydrate and $0.7 \mathrm{~g}$ potassium chloride into 
one liter of MQ water. The solution was adjusted to $\mathrm{pH} 8.2$ with $0.1 \mathrm{M} \mathrm{NaOH}$, and filtered with a $0.2 \mu \mathrm{m}$ membrane filter (Nalgene, USA).

Preparation of SAMs. $25 \AA$ adhesion-promoting titanium and $300 \AA$ gold were coated onto glass substrates by electron-beam physical vapor deposition under vacuum. The goldcoated glass substrates were TL1-cleaned (1:1:5 proportions of $25 \% \mathrm{NH}_{3}, 30 \% \mathrm{H}_{2} \mathrm{O}_{2}$, and MQ water) for $10 \mathrm{~min}$ at $85^{\circ} \mathrm{C}$. After rinsing several times under running MQ water, the surfaces were blow-dried in an $\mathrm{N}_{2}$ stream. Cleaned gold substrates were immersed in 50 $\mu \mathrm{M}$ solutions of $\alpha$-bromoisobutyrate-11-mercapto-undecane in ethanol for $24 \mathrm{~h}$ to form initiator monolayers. The samples were then rinsed with ethanol and water and then blow dried in $\mathrm{N}_{2}$ stream as described above, before use. Formation of $\mathrm{CH}_{3}$-terminated SAMs from 1-octadecanethiol, and of $\mathrm{EG}_{6}$-terminated SAMs from 1-mercaptoundecyl oligo ethylene glycol, were performed in a similar manner.

Preparation of PDMAEMA coatings. The PDMAEMA homopolymers were prepared via surface-initiated atom transfer radical polymerization (SI-ATRP). Briefly, a reaction solution of $2.41 \mathrm{mM}$ copper bromide and $4.68 \mathrm{mM}$ 2,2'-bipyridine in MQ water was placed in a sealed glass reactor in a glovebox under $\mathrm{N}_{2}$ atmosphere. Then, $200 \mathrm{mM}$ of degassed DMAEMA solution in a mixing solvent (MQ water and methanol at a 1:1 volume ratio) was transferred to the reactor. Gold substrates with initiator-SAMs were then placed into the reactor under $\mathrm{N}_{2}$ protection at room temperature $\left(20^{\circ} \mathrm{C}\right)$ for one hour, resulting in a polymer film thickness of approximately $105 \AA$. After polymerization, samples were removed and rinsed with water and methanol, and the samples were then kept in water overnight to leach out unreacted monomers and catalyst. XPS analysis after overnight leaching did not show any indication of residual copper ions (see Supplemental Material). Polymer surface characterization. The chemical structure of PDMAEMA was recorded by a Fourier-transform infrared reflection-absorption spectroscopic (FT-IRAS) system using a grazing angle of $85^{\circ}$. The spectrometer (Bruker IFS66) was equipped with a liquid nitrogen-cooled mercury cadmium telluride detector. A deuterated hexadecanethiol $\left(\mathrm{HS}\left(\mathrm{CD}_{2}\right)_{15} \mathrm{CD}_{3}\right) \mathrm{SAM}$ on gold was used to record the background spectrum. Polymer film thicknesses were determined with a Rudolph Research AutoEL ellipsometer, with a HeNe laser $(632.8 \mathrm{~nm})$, at $70^{\circ}$ angle of incidence. The refractive index of the TL1-cleaned gold 
substrates were measured before SAM formation. To determine the polymer thicknesses, a three-layer optical model (ambient/organic film/gold) was used, where the refractive index of the organic film was set to 1.5. Five different spots were measured on each sample, and the average was calculated as the polymer film thickness. The surface wettability of PDMAEMA was assessed by static water contact angle measurement in air and under water (captive bubble contact angle) using a CAM 200 Optical Contact Angle Meter (KSV Instruments Ltd., Finland) equipped with a manual liquid dispenser. Three points were measured on each sample. The influence of $\mathrm{pH}$ on the captive bubble contact angle was also observed; after equilibrating the polymer films in MQ water at $\mathrm{pH}$ values between 3 and 12 (unbuffered; adjusted by adding $\mathrm{HCl}$ or $\mathrm{NaOH}$ to the $\mathrm{MQ}$ water), the samples were placed facing downwards in a quartz cell filled with MQ water with $\mathrm{pH}$ as above. Around $2 \mu \mathrm{l}$ air bubbles were manually released and allowed to rise onto the surface from a Ushaped needle. Three contact angles were measured and averaged. Captive-bubble contact angles in ASW and with $n$-octane droplets were acquired using a Dataphysics OCA35 contact angle analyzer with SCA22 software. The surface energies of the hydrated samples were determined from captive bubble contact angles of air and $n$-octane, obtained as above. Prior to measurement, the samples were equilibrated in MQ water, and the samples were then placed facing downwards in a glass cell filled with water. Three contact angles each were measured for air $\left(\theta_{a}\right)$ and n-octane $\left(\theta_{0}\right)$, and averaged. The surface energies were calculated using the Owens \& Wendt approach (Owens \& Wendt 1969) applied to underwater contact angles. (Roudman \& DiGiano 2000)

Hydration and swelling. The influence of solution $\mathrm{pH}$ on hydration and swelling of PDMAEMA was measured both in Milli-Q water and ASW using a Q-Sense E4 quartz crystal microbalance with dissipation (QCM-D). AT-cut quartz crystal sensors (Q-Sense, Göteborg, Sweden) with gold electrodes, a fundamental resonant frequency of $4.950 \mathrm{MHz}$ and a diameter of $14 \mathrm{~mm}$ were coated with PDMAEMA via SI-ATRP as described above. The quartz crystals were then mounted in the QCM-D fluid cell, and data was recorded at three different overtones $\left(3^{\text {rd }}, 5^{\text {th }}\right.$ and $\left.7^{\text {th }}\right)$ at $22{ }^{\circ} \mathrm{C}$. After 10 minute recording in dry air

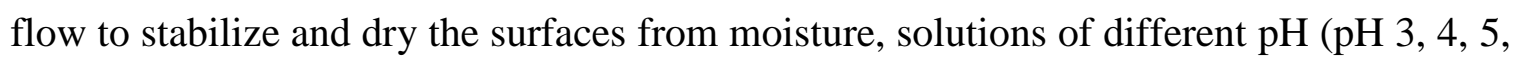
$6,7,8,9,10,11$ or 12$)$ were added sequentially at a constant flow rate $(0.3 \mathrm{~mL} / \mathrm{min})$. The frequency changes $(\Delta f)$ and dissipation changes $(\Delta D)$ in water were then recorded, and 
presented in the following using the uncoated sensor as reference. The obtained frequency and dissipation differences measured between uncoated and polymer-coated sensors were defined as $\Delta f_{\text {film }}$ and $\Delta D_{\text {film }}$, respectively. The $\Delta f$ and $\Delta D$ data were analyzed using QTools v3.1.24 software.

Settlement of spores of Ulva. The zoospore settlement assays followed a published protocol (Callow et al. 1997). Reproductive plants of the marine alga $U$. linza were collected from Llantwit Major beach, Wales, UK (51.3961N; 3.5015W). Plants of U. lactuca were collected from a site near the Sven Lovén Centre for Marine Sciences, Tjärnö, Sweden (58.8625N; 11.1308E). The motile spores were released and the concentration adjusted to $\mathrm{OD}_{600 \mathrm{~nm}}=0.15\left(1.0 \times 10^{6}\right.$ spores $\left.\mathrm{ml}^{-1}\right)$ using filtered ASW. Three replicates of PDMAEMA, $\mathrm{EG}_{6} \mathrm{SAM}, \mathrm{CH}_{3} \mathrm{SAM}$, and Nexterion glass controls were placed separately in polystyrene Quadriperm dishes (Greiner Bio-One Ltd.) and equilibrated for $1 \mathrm{~h}$ in filtered ASW prior to the assay. After removing the ASW, $10 \mathrm{ml}$ of spore suspension were added to each well, followed by incubation for $45 \mathrm{~min}$ in the dark at room temperature. After washing with filtered ASW, the samples were fixed in $10 \mathrm{ml}$ of $2.5 \%$ glutaraldehyde in filtered ASW for $20 \mathrm{~min}$ at room temperature. The samples were then washed in sequence with filtered ASW, filtered ASW/deionized water (1:1 volume ratio), deionized water and finally airdried. The number of settled (adhered) spores was determined by chlorophyll autofluorescence using an AxioVision 4 image analysis attached to a Zeiss epifluorescence microscopy (20 x objective; $\lambda_{\text {ex/em }} 546$ and $590 \mathrm{~nm}$, respectively) and a video camera. A total of 30 fields of view, each taken at $1 \mathrm{~mm}$ intervals along the slide, was counted for each of the three replicates.

Observations of pseudosettled spores of Ulva. Pseudosettlement of spores on PDMAEMA was analyzed quantitatively by using an inverted optical microscope. For the quantitative analysis, 10 images of settled spores were acquired randomly on each replicate, and each type of spore counted manually. Normally settled spores are characterized by rounded shape, while pseudosettled spores are characterized by a pear-shape with unretracted flagella (characteristic of motile spores), and disrupted spores are irregularly shaped 'attached' spores. Qualitative analysis of the pseudosettled spores was made from images 
obtained on a Phenom desktop scanning electron microscope (SEM) (FEI, Eindhoven, Netherlands).

Growth of sporelings of Ulva. The reproductive plants of $U$. linza for the sporeling growth assay were collected from Boulmer, England, UK (55.4398N; $1.5893 \mathrm{~W})$ and U. lactuca were collected as above. The collected plants were transported overnight in seawater from the collection sites to Linköping. Spores were released and allowed to settle on the test surfaces as described in the previous section. Ten $\mathrm{ml}$ of enriched seawater medium (Starr \& Zeikus 1993) were added to each dish compartment. The dishes were incubated at $23{ }^{\circ} \mathrm{C}$ with a 16 h:8 h, light:dark cycle. The medium was replaced after $24 \mathrm{~h}$ and then every 2 days. The sporelings (young plants) were harvested by scraping with a razor blade after 3 or 8 days incubation. Biomass was determined by extraction of chlorophyll in DMSO (Pettitt et al. 2004). The amount of extracted chlorophyll $a$ was determined spectrophotometrically (using absorptions at 664 and $647 \mathrm{~nm}$ ) via the Jeffrey and Humphrey equation (Jeffrey \& Humphrey 1975).

Statistical analysis. The settlement densities of spores are presented as the number of settled spores per $\mathrm{mm}^{2}$ with $95 \%$ confidence limits. Sporeling growth on PDMAEMA is presented as the biomass, as inferred from the chlorophyll $a$ content, and also scaled with the settlement data. Error bars represent the standard deviation from 3 replicates of each sample. Statistical analysis of spores settlement and sporelings data for $U$. linza was carried out using Minitab 16 statistical software, One way Analysis of Variance (ANOVA) with $\alpha$ $=5 \%$ and Tukey's HSD Post-hoc tests were performed to determine the difference between samples. Values were considered significantly different from each other when $p$-value $(p)$ $<0.05$.

\section{Results and Discussion}

\section{Polymer preparation and characterization.}

PDMAEMA homopolymer was prepared via SI-ATRP (Figure 1) to about $100 \AA \AA$ thickness, after one hour polymerization in a water-methanol mixture $(1: 1 \mathrm{v} / \mathrm{v})$. This reaction rate is relatively slow compared to other hydrophilic polymers, such as PEG-based materials, due 
to the poor solubility of DMAEMA in water at neutral $\mathrm{pH}$. Ellipsometric dry thicknesses of the used coatings are included in Table 1. The wettability of PDMAEMA was determined by contact angles measured both on dry (in air) and hydrated films (under MQ water and in ASW). As shown in Table 1, the MQ water contact angle on PDMAEMA at $\mathrm{pH} 7$ (MQ water adjusted to $\mathrm{pH}$ 7) was approximately $74^{\circ}$ in air, indicating that the interaction between PDMAEMA and water was relatively weak. The underwater (captive bubble) contact angle was $134^{\circ}$. Due to the inverse geometry, this can be compared to the contact angle in air if subtracted from $180^{\circ}$, resulting in an angle of $180^{\circ}-134^{\circ}=46^{\circ}$. This is considerably lower than the air contact angle, indicating that the surface is strongly hydrated and/or swollen upon immersion in water, and that it likely exposes different functional groups at the interface in the two environments. The captive-bubble contact angle of hydrated PDMAEMA in ASW (pH 8.2) was $121^{\circ}$, giving $59^{\circ}$ after subtraction from $180^{\circ}$, indicating a wettability between that in air and in MQ water at $\mathrm{pH} 7$. This lower underwater angle at higher $\mathrm{pH}$ and salinity, might be a result of dehydration of PDMAEMA by the strong electrolyte and increased hydrophobicity due to a reduced number of ionized dimethylammonium groups. Surface energy measurements showed lower surface energy of hydrated PDMAEMA than that of glass and the $\mathrm{EG}_{6} \mathrm{SAM}$, but still higher than the hydrophobic $\mathrm{CH}_{3} \mathrm{SAM}$.

The FT-IRAS spectra of PDMAEMA and the initiator SAM (Figure 2) confirmed that DMAEMA was successfully polymerized onto the initiator surfaces. Asymmetric and symmetric C-H stretching bands of $\mathrm{CH}_{2}$ and $\mathrm{CH}_{3}$ were observed at $2962-2846 \mathrm{~cm}^{-1}$ in both, the initiator SAM and the PDMAEMA spectra. C-H stretching vibrations of tertiary dimethyl amine (-N-(CH 3$\left.)_{2}\right)$ was observed at 2822 and $2770 \mathrm{~cm}^{-1}$ and were absent in the initiator SAM spectrum, indicating the presence of DMAEMA on the surface. There is also an associated increase in the number and intensity of methyl and methylene deformation modes in the range $1500-1350 \mathrm{~cm}^{-1}$. A prominent ester carbonyl stretching vibration in the PDMAEMA was observed at $1736 \mathrm{~cm}^{-1}$, whereas the corresponding absorption for the initiator SAM occurs at $1738 \mathrm{~cm}^{-1}$, and at a considerably lower intensity (note the differences in scale between the spectra in Figure 2). Furthermore, skeletal C-O-C vibrations of PDMAEMA and initiator SAM were found over $1100-1170 \mathrm{~cm}^{-1}$. C-N stretching vibration was observed at $1154 \mathrm{~cm}^{-1}$ in PDMAEMA and was absent in the 
initiator-SAM spectrum. The broad O-H stretching band in the initiator SAM, extending over 3500-3100 $\mathrm{cm}^{-1}$ due to hydrogen bonding, is present also in PDMAEMA, but not clearly visible in Figure 2 due to the scale difference. We also note the absence of the $\mathrm{C}=\mathrm{C}$ stretching of unreacted methacrylate in the PDMAEMA spectrum, which would be expected at 1640-1630 $\mathrm{cm}^{-1}$. Overall, these results are consistent with successful grafting of PDMAEMA from the initiator SAM.

The polymer brushes have not been characterized with respect to chain length and grafting density. Literature in the field (Timofeeva \& Kleshcheva 2011) indicates that many other parameters, such as local surface density and distribution of charged groups (Huang et al. 2008), total grafted amount (Huang et al. 2007), as well as steric availability due to $\mathrm{pH}$ changes (Jia et al. 2012, Yandi et al. 2016) affect the biocidal activity. Other studies found that the killing efficiency of cationic surfaces was independent of both polymer layer thickness and grafting density (Madkour et al. 2009), and a more detailed characterization of possible effects of chain length and grafting density on the antialgal effects has thus been left for future studies.

The stability of the PDMAEMA coatings were tested by immersion in MQ water and filtered ASW for 14 days. Storage under MQ water did not result in any significant changes in the IRAS spectra, whereas ASW induced a slight redistribution of peak intensities already after 1 day, but which did not change further during 14 days of monitoring (see the Supplemental Material for details). We believe that these changes result from interactions of ions from the ASW with the polymer, which cannot be washed out.

\section{Settlement of spores of Ulva and microscopic observations of settled spores.}

To study the interactions of zoospores of the marine algae $U$. linza and $U$. lactuca with different surface chemistries, settlement assays were performed on PDMAEMA, EG6 SAMs, $\mathrm{CH}_{3} \mathrm{SAMs}$ and glass slides. The density of settled (ie total attached) spores was found to differ significantly with surface type (ANOVA, $p<0.05$ ). High settlement of spores was found on $\mathrm{CH}_{3} \mathrm{SAMs}$, glass and PDMAEMA, and only very few spores settled on the $\mathrm{EG}_{6}$ SAM surface (Figure 3). More precisely and considering both algal species, the settlement density was significantly the highest on $\mathrm{CH}_{3} \mathrm{SAMs}$ and the lowest on $\mathrm{EG}_{6}$ 
SAMs while the results between glass and PDMAEMA were significantly different for $U$. lactuca but not for $U$. linza (Tukey's pairwise comparisons, $\mathrm{p}<0.05$ ). The results for the SAMs and glass substrates are in good agreement with previously published data (Callow et al. 2000, Schilp et al. 2007), and the high settlement onto PDMAEMA is consistent with our previous results (Yandi et al. 2016), and results from other cationic surfaces (Park et al. 2010). The general characteristics of the spores attached onto PDMAEMA and $\mathrm{CH}_{3}$ SAMs, as observed under a fluorescence microscope, are compared in Figure 4. On PDMAEMA, attached spores were bright and distributed as single cells, or as small clusters of cells. A large number of single spores with weak fluorescence intensity was also observed in some areas. These "shaded" spores were later confirmed by scanning electron microscopy (SEM) to be remnants of ruptured spores (Figure 5). In contrast to PDMAEMA, the settlement of spores on the hydrophobic $\mathrm{CH}_{3} \mathrm{SAM}$ was characterized by aggregation, with most spores being found in clumps on the surface, with a smaller number present as single spores. Settlement was overall high on both $\mathrm{CH}_{3}$ SAMs and PDMAEMA surfaces, but it is likely that the reason for the high settlement is different for the two surfaces. It is known that zoospores of Ulva have a settlement preference for hydrophobic surfaces (Callow et al. 2000, Finlay et al. 2002), explaining the result on the $\mathrm{CH}_{3} \mathrm{SAM}$, and previous tests also show high settlement onto PDMAEMA surfaces (Yandi et al. 2016), though in the latter case direct electrostatic attraction between the negatively charged spore and the surface is thought to be a major reason, as has also been discussed on other types of cationic surfaces (Ederth et al. 2008, Ederth et al. 2009). However, since the settlement assay was performed in ASW at $\mathrm{pH}$ 8.2, where the charge of PDMAEMA is likely to be reduced due to partial deprotonation of DMAEMA segments (see further discussion on this below), hydrophobic interactions might also contribute to the high settlement.

To better understand the process of settlement of spores on the cationic PDMAEMA surface, samples with attached spores were analyzed by both light microscopy and SEM. Beside the rounded shape of normally settled spores, we observed pseudosettlement, resulting in pyriform, irregular, or disrupted spores, and also detached flagella (Figure 5). From assessment under the light microscope, the density of attached spores was divided into three categories, ie, normal settled spores having a rounded shape and withdrawn flagella; pseudosettled spores, where the attached spores are pyriform, apparently attached 
side-on to the surface, sometimes still retaining the flagella; and disrupted cells, where the spore shape is irregular and fluorescence weak. It was assessed that around $60 \%$ of spores were normally settled spores, $21 \%$ attached as 'pseudosettled' spores and $19 \%$ were found as disrupted cells.

The settlement of the motile Ulva spore starts with exploration of the surface during which, the 'naked' spore (ie the spore is only bounded by a lipoprotein plasma membrane) attaches to the surface via its apical papilla, and undergoes rapid 'top-like' spinning. The spore may then detach and undergo further surface exploration, or may commit to permanent settlement. In the latter case, retraction of flagella and adhesive secretion initiates the irreversible permanent settlement as a non-motile round-shaped spore (Figure 6a), (Callow \& Callow 2006). The attached spore also secretes a polysaccharide-rich cell wall. We hypothesize that positive charges on the PDMAEMA could lead to attractive electrostatic interactions with the negatively charged spore membrane, and that this attraction causes the spore body to attach directly, and sometimes side-on, to the cationic PDMAEMA surface (Figure 6b), leading to pseudosettlement, ie adhering to the surface without undergoing the normal morphological transformation associated with settlement. Since the flagella are also surrounded by the plasma membrane, contact between the surface and one or more of the four flagella probably accounts for the detached flagella seen in Figure 5. Only around 20 percent of the spores were found to be attached to PDMAEMA via such pseudosettlement, which is much lower than what was found on cationic peptide SAMs, where 50 percent pseudosettlement was observed (Ederth et al. 2008). In ASW at pH 8.2, PDMAEMA is partially ionized and behaves like an amphiphilic polymer due to the presence of hydrophobic segments (Liu et al. 2007). The hydrophobic character might enhance the settlement of spores, due to a positive correlation between settlement and hydrophobicity (Callow et al. 2000). The lower frequency of pseudosettled spores, compared to the cationic peptide SAMs, could be a result of lower cationic surface charge. Detached flagella on the PDMAEMA indicate electrostatic (possibly in combination with hydrophobic) entrapment of flagella on the polymer surface during exploration (Figure 6d). Disruption of attached spores (Figure 6c) might be a result of direct interaction of the spore membrane with the cationic surface, similar to the mechanisms that 
give PDMAEMA antimicrobial activity (a more detailed discussion on this issue follows below). These types of pseudosettlement of Ulva spores have so far been reported only on some types of cationic surfaces (Ederth et al. 2008, Ederth et al. 2009, Yandi et al. 2016), and it seems reasonable to assume that this is driven mainly by electrostatic interactions. After attachment to the surface, it is possible that electrostatic and/or hydrophobic interactions with the polymer leads to the disruption of the spore membrane, and release of cellular material, leaving behind residues with reduced fluorescence intensity and deflated morphology, as observed in Figure 4 and Figure 5 (Huang et al. 2008, Rawlinson et al. 2010). Hydrophobic interactions act over distances of the order of the length of hydrogen bonds, and in ASW, where the Debye screening length is a few $\AA$, electrostatic forces are significant only over similar distances. For these interactions to be relevant to the disruption of the spore membrane, the spores have to be in contact with the surface. Once within reach of the polymer chains, the spore membrane might be disrupted by penetration or partitioning of the polymer chains into it, or by extraction of anionic membrane components. Note that this interaction is distinctly different from the possible role of cationic residues in the settlement process, as has been discussed in previous papers, where effects on spore swimming activity in the volume of seawater above cationic surfaces have been observed (Vater et al. 2015).

However, the physical state of PDMAEMA changes dramatically with protonation of the amino groups, and thus varies with the $\mathrm{pH}$. In order to assess the state of the PDMAEMA layer at the $\mathrm{pH}$ of seawater (8.2), we have investigated the physicochemical properties of PDMAEMA over a wider range of $\mathrm{pH}$ values.

\section{Hydration, swelling and wettability of PDMAEMA at different $\mathrm{pH}$}

Interactions between ions and water molecules are important for the understanding of fouling and antifouling mechanisms of polyelectrolytes. An ion in water reorganizes surrounding water molecules, breaking the hydrogen bond network in the formation of a hydration shell, which could sometimes extend a few water molecules from the ion. Ammonium ions interact strong enough with water to re-organize the latter into a tetrahedrically coordinated hydration shell (Dang 1993). We have studied the hydration of 
the ammonium ions in PDMAEMA at different $\mathrm{pH}$ with QCM-D. The resonance frequencies of crystals with PDMAEMA layers $\left(\Delta f_{\text {film }}\right)$ change considerably with changes in $\mathrm{pH}$ (Figure 7a). An interpretation in terms of $\mathrm{pH}$-dependent coupling or decoupling of water molecules in the PDMAEMA layer, leading to hydration or dehydration of the PDMAEMA film, is consistent with the $\mathrm{pH}$-changes observed in previous experiments (Burillo et al. 2007, Lee et al. 2011). As the pH varies, the hydration of PDMAEMA is changed due to changes in the solvation of the ammonium ion, leading to strong coordination of water molecules in its protonated ionic state at low $\mathrm{pH}$, but resulting in a hydrophobic moiety in its deprotonated state at high $\mathrm{pH}$. This is confirmed by the QCM data in Figure 7a. In the highly acidic environment at $\mathrm{pH}$, the hydration was high, due to full ionization of ammonium ions, as is evident from the large negative value of $\Delta f_{\text {film }}$ and the large dissipation, indicating mass coupling to the surface. Under these conditions, fully cationized ammonium ions will coordinate water molecules around each side chain and cause swelling of the film. As the $\mathrm{pH}$ is increased to 5 , there is a sharp increase in $\Delta f_{\text {film }}$, followed by a slower increase up to $\mathrm{pH} 10$, as a result of the transition from full ionization to partial ionization of ammonium ions. A reduction in the number of protonated ammonium ions leads to loss of hydration, loss in adsorbed mass, and thus also a smaller frequency shift. In the highly basic environment at $\mathrm{pH}>10$, the magnitude of $\Delta f_{\text {film }}$ is small, showing that PDMAEMA remains collapsed and dehydrated as a result of deprotonation of ammonium ions. The deprotonation and the associated loss of the hydration shell is also accompanied by increased exposure of the terminating methyl groups on the polymer side chains, and hydrophobic interactions between these also allow for an increase in the interchain stabilization of the polymer film.

The swelling of a grafted polymer can be assessed by comparing the wet thickness (TW) obtained by modelling of the QCM-D data using a one-layer Voigt model, and the dry film thickness (TD) measured by, for example, ellipsometry. This yields the swelling as

$$
\text { Swelling }(\%)=\frac{\mathrm{TW}-\mathrm{TD}}{\mathrm{TD}} \times 100 \%
$$

While this will not result in a quantitatively accurate measure of the swelling, due to the differences in the 'thickness' quantities that are obtained via ellipsometry and QCM 
(Plunkett et al. 2003), it will still yield a qualitatively useful result. As is shown in Figure 7b, swelling of PDMAEMA decreases upon increasing $\mathrm{pH}$, supporting the view that water uptake at high $\mathrm{pH}$ is much less than at low $\mathrm{pH}$, presumably due to loss of hydration, as mentioned above. This is further supported by viscoelastic modelling of the data at different $\mathrm{pH}$ values in the one-layer Voigt model. Both viscosity and elasticity of PDMAEMA decrease when $\mathrm{pH}$ is changed from acidic to basic (Figure 7c). The decrease of viscosity is moderate in relative terms, about $10 \%$, while the loss of elasticity is more dramatic, near 95\%. Again, this results from de-coupling of water molecules around the cations as a result of deprotonation of ammonium ions under basic conditions, leading to increased inter- and intrachain interactions, effectively acting as weak (non-covalent) crosslinking. The incomplete decrease in viscosity at $\mathrm{pH} 8.2$ supports the view that the polymer retains a considerable fraction of water in the polymer, presumably trapped as hydration water surrounding charged residues.

The wettability of hydrated PDMAEMA was studied by underwater captive bubble contact angle measurements at different $\mathrm{pH}$. The underwater contact angle of hydrated PDMAEMA varies from $144^{\circ}$ in a highly acidic environment to $124^{\circ}$ in the basic environment when $\mathrm{pH}>10$ (Figure $7 \mathrm{~b}$ ). Deducing these angles from $180^{\circ}$ to obtain angles comparable to sessile drop measurements, this is a change from $36^{\circ}$ at low $\mathrm{pH}$ to $56^{\circ}$ at high $\mathrm{pH}$, showing that the wettability of hydrated PDMAEMA is decreasing as the $\mathrm{pH}$ is increasing. Such a change might be a result of reorganization of the polymer near the interface as the environmental conditions are varied, but in view of the considerable change in swelling with $\mathrm{pH}$, it is more likely in this case that this results from the change in the interaction between water molecules and ammonium ions, and an ensuing increase in the number of exposed methyl groups at the interface, as described above. However, the wettability of hydrated PDMAEMA is still much higher than that of the $\mathrm{CH}_{3}$ SAM surface (underwater $\mathrm{CA} 56^{\circ} \pm 2$ ), even at the highest $\mathrm{pH}$ (12), due to the presence of acrylate oxygen moieties and the amine groups, which are still more polar than the $\mathrm{CH}_{3}$ acyl chains. Summarizing the results in Figure 7, we find that the PDMAEMA layer is dehydrated at $\mathrm{pH}$ 8.2, but not totally collapsed, indicating that the polymer still retains charged (polar) residues at the $\mathrm{pH}$ of the ASW. This is in agreement with published results for PDMAEMA, showing that at $\mathrm{pH} 8.2$, the degree of ionization is approximately $10 \%$, which increases 
slightly with salinity due to reduced interaction between charged residues ( Lee et al. 2011). Reported pKa values of about 8 (Bruining et al. 2000) and low, but positive, zeta-potentials of approximately $+10 \mathrm{mV}$ at pH 8.2 (Chen et al. 2013) are also consistent with our findings. Hence, with a large fraction of neutralized amino residues, there is likely to be a hydrophobic contribution that promotes spore attachment, in addition to the direct electrostatic attraction between the oppositely charged surface and the algal cell membrane.

\section{Inhibition of the growth of sporelings of Ulva}

After spore settlement the permanently adhered, unicellular spore of Ulva spp. germinates to produce multicellular sporelings (young plants). The growth of such sporelings of $U$. linza and U. lactuca, on PDMAEMA, $\mathrm{CH}_{3}$ SAMs, EG 6 SAMs and glass was studied, and the biomass assessed by measurements of the chlorophyll $a$ content after incubation for 3 and 8 days in enriched seawater, with the outcome shown in Figure 8. Overall, the trends between different samples were very similar for the two algal species, though there is a systematic difference in the absolute biomass since the highest biomass was obtained with U. lactuca on all the surfaces tested. Nested ANOVA analysis confirms significant differences between the samples ( $\mathrm{p}<0.05)$, and all measured biomasses after 3 days were significantly different from each other. Biomasses measured after 8 days were also significantly different from each other, with the exception of the results for glass and $\mathrm{CH}_{3}$ SAM samples for $U$. lactuca after 8 days of sporelings growth, which were not distinguishable (Tukey’s pairwise comparisons, $\mathrm{p}<0.05$ ).

Despite the high settlement of spores onto the PDMAEMA samples, sporeling growth was limited, and was significantly lower than on the $\mathrm{CH}_{3} \mathrm{SAM}$ and the glass substrates. Taking into account that the numbers of settled spores were different on the samples, we normalized the biomass with the spore settlement density, and obtained the amount of chlorophyll $a$ per settled spore, shown in Figure 9. From this figure, it is clear that both the generated biomass per spore after 3 days was lower on PDMAEMA than for any other substrate, and also that the growth was slower, as indicated by shown percentage increases between 3 and 8 days. The spore density used for PDMAEMA in Figure 9 is the total

number of spores, but taking into account also that only about $60 \%$ of the spores on 
PDMAEMA were settled normally and thus have the potential for germination and growth, it is still clear that sporeling growth was severely restricted on this material. The dashed lines over the results for PDMAEMA in Figure 9 show the biomasses obtained if the actual results are compensated for the reduced number of normally settled spores (ie divided by 60\%). This demonstrates that although PDMAEMA induces massive spore settlement, this surface is unfavorable for the development and growth of spores into sporelings. Krishnan et al demonstrated that pyridinium polymers with fluorinated side-chains inhibit the growth of sporelings of $U$. linza (Krishnan et al. 2005), and Park et al. made a similar observation on semi-fluorinated quaternized triblock copolymers (Park et al. 2010). The toxicity of quaternary ammonium compounds is well documented (Tischer et al. 2012), but Park suggested that the growth inhibition might be caused by the high density of settled spores, competing for space and nutrients, on the tested samples. Our data show that this does not explain the results for PDMAEMA, since both glass and the $\mathrm{CH}_{3}$-terminated samples had similar, or higher, spore densities, but nevertheless had much higher sporeling biomass, demonstrating that the inhibition in the growth was a result of the surface. However, we do not know yet whether the reduced sporeling biomass on PDMAEMA was actually caused by inhibition, or due to killing of the spores. Normal morphogenesis and growth of sporelings of Ulva species have been shown to require the presence of naturally occurring bacteria (Marshall et al. 2006). It is therefore also possible that an anti-bacterial action of the surface could have resulted in the loss of beneficial bacteria resulting in a retarded sporeling growth rate. Bacteria would also proliferate where there are damaged (dead) cells, and this would impact the development of 'normal' spores on this surface.

\section{Possible mechanisms of action regarding antialgal activity of PDMAEMA}

The literature on contact-active cationic macromolecules for antimicrobial purposes is extensive (see eg Timofeeva (Timofeeva \& Kleshcheva 2011) or Muñoz-Bonilla (MuñozBonilla \& Fernández-García 2012) for reviews). Cationic materials have been developed that are effective against Gram-positive and Gram-negative bacteria, viruses, yeast and other fungi (Muñoz-Bonilla \& Fernández-García 2012), despite the very different cell envelopes of these microbial families. Few studies on materials with algicidal contact 
activity are available, but there are examples of bactericidal coatings which have been tested on diatoms, with no algicidal effects (Kugel et al. 2009, Park et al. 2010). Diatoms are microalgae enclosed in a silica cell wall, the frustule, and it appears that this provides efficient shelter against non-leaching, contact-active, coatings. However a number of other studies have suggested that it is difficult to generalize such effects. Pranantyo et al. (Pranantyo et al. 2015) demonstrated reduced attachment density of the diatom Amphora coffeaformis on cationic poly[2-(methacryloyloxy) ethyl]trimethylammonium chloride surfaces and Subramanyam et al. demonstrated that benzaldehyde derivatives copolymerized with methyl methacrylate had contact toxicity against microalgae, including the diatoms Amphora coffeaeformis and Navicula incerta (Subramanyam et al. 2009). Two previous studies have shown inhibitory effects of cationic polymers on $U$. linza sporeling growth, but in contrast to our data, neither reported any contact activity that immediately affected zoospore viability (Krishnan et al. 2005, Park et al. 2010). Ye et al (Ye et al. 2012) reported that, depending on the counter-ion, some cationic brushes of poly[2-(methacryloyloxy)ethyl]trimethylammonium chloride on titanium increased attachment of unicells of the green alga Chlorella. However, the relevance of this to the present study is not clear since although both Chlorella and Ulva are members of the Chlorophyta, unlike Ulva spp. which require adhesion of motile spores to a solid surface to complete their life cycle, the non-motile cells of Chlorella are essentially planktonic and do not exhibit a specific adhesion phase in their life history. Furthermore, unlike spores of Ulva spp., cells of Chlorella are surrounded by a polysaccharide-rich cell wall (Northcote et al. 1958).

The mechanisms by which cationic polymers lead to cell death are poorly understood, and in some cases it is not even clear whether the effect is merely inhibitory. A number of mechanisms have been suggested to account for the antimicrobial properties of cationic materials, most involve membrane rupture via penetration of polymer chains or by exchange of divalent membrane cations (Timofeeva \& Kleshcheva 2011), through extraction of phospholipids from the membrane (the 'phospholipid sponge effect') (Bieser \& Tiller 2011), or indirectly by triggering cell death mechanisms (Hilpert et al. 2009). It is clear that factors such as charge density, chain mobility, molecular weight and hydrophobicity affect the performance of the polymers. Specifically, a study where the 
chain length and grafting density of quaternized PDMAEMA were varied, highlighted the role of surface charge density (Murata et al. 2007). Rawlinson et al. found that PDMAEMA was active against Gram-positive bacteria near its $\mathrm{pKa}$ and at lower $\mathrm{pH}$, and against Gramnegative bacteria around its pKa and at higher pH values (Rawlinson et al. 2010). Clearly, environmental parameters should be added to the parameter space, in addition to microbe species and polymer properties.

For our purposes, it is relevant to establish to what extent the membrane compositions of green algae differ from those of the microbes that are the usual targets for antimicrobial coatings. Ulva spores do not have a cell wall, but expose the lipoprotein plasma membrane to the surroundings, though little is known about the exterior of this membrane. Glycoconjugates of $U$. flexuosa and $U$. fasciata have been determined and compared, finding primarily mannose and glucose moieties on the plasma membrane (Michael 2009), and these glycoconjugates are likely to provide a weaker barrier to macromolecular penetration than the outer membranes or the peptidoglycan envelopes in bacteria. Total lipid content of Enteromorpha intestinalis (=Ulva intestinalis) has been determined (Jones \& Harwood 1993), showing that glycosylglycerides form $75 \%$ of the acyl lipids, and with phosphatidylglycerol being the only important phospholipid. Glycosylglycerides constitute a major group of glycolipids in both plants and microorganisms, including Gram-positive, Gram-negative, and also some photosynthetic bacteria, but are not common in animals. This points to some - albeit superficial - similarities between the membranes of algal spores and microorganisms. However, phosphatidylglycerol is an anionic lipid, adding negative charge to the membrane. The negative charge of $U$. linza spore membranes was established via measurement of the zeta potential, yielding $-19 \mathrm{mV}$ (Rosenhahn et al. 2009). Since the negative surface charge is the primary source of selectivity between the membranes of microbes and mammalian cells, we speculate that the mechanisms of antialgal action might be found among those also suggested for antimicrobial action. However, we do not yet have any data indicating whether any of the mechanisms proposed for microbes are more probable than any other, but anticipate that further work will enlighten this issue. 


\section{Conclusions}

We investigated the antialgal activity of brushes of the polymer poly(2(dimethylamino)ethyl methacrylate), which is weakly cationic at the $\mathrm{pH}$ of ASW, and use methyl- and oligoethyl-terminated SAMs, as well as glass surfaces, for comparisons. Using zoospores of $U$. linza and $U$. lactuca, we performed settlement and sporeling growth assays, to investigate the spore settlement behaviour, and sporelings growth inhibition. Results were very similar for both species of Ulva. While spore settlement onto the cationic PDMAEMA polymer brushes was high, a large portion of the spores on the surface was clearly disrupted, or otherwise pseudosettled, which was not observed on the other materials, demonstrating that the PDMAEMA interferes with the settlement process of Ulva zoospores. We hypothesize that this is related to a combination of electrostatic and hydrophobic interactions with the cationic polymer brush, which is partially dehydrated at the $\mathrm{pH}$ of seawater (8.2) and thus rendered partially hydrophobic through deprotonation of the dimethyl amine groups. We also demonstrate that PDMAEMA inhibits the growth of sporelings of both algal species. The sporeling biomass after a 3-day growth period was significantly lower on PDMAEMA than on hydrophobic $\mathrm{CH}_{3} \mathrm{SAM}$ and glass, though settlement was similar, or higher, on these substrates. Scaling the biomass to the number of settled spores on each surface, we still find that the biomass was, by far, the lowest on the PDMAEMA surfaces, and also that growth between 3 and 8 days was much slower on this surface. Hence, we conclude that PDMAEMA brushes have antialgal activity against Ulva, in that it has the capacity to both kill zoospores that come into contact with the brushes, and to also inhibit growth of spores that have settled normally. We foresee that through further development, contact-active antialgal coatings would be a future possibility. 


\section{Acknowledgements}

We thank Gunnar Cervin and Henrik Pavia for assistance at the The Sven Lovén Centre for Marine Sciences at Tjärnö, Pierre Martin-Tanchereau and Lyndsey Tyson at Akzo Nobel Performance Coatings Research for assistance with the captive-bubble contact angle measurements, and Jing Jin for assistance with sample preparation. This work was supported by the European Community’s Seventh Framework Program FP7/2007-2013 under Grant Agreement 237997 (SEACOAT). TE acknowledges financial support from the Swedish Government Strategic Research Area in Materials Science on Functional Materials at Linköping University (Faculty Grant SFO-Mat-LiU \# 2009-00971).

\section{Supplemental Material}

FT-IRAS data on the stability of PDMAEMA in ASW and MQ water, and XPS data for a PDMAEMA brush, are available in the Supplemental Material. 

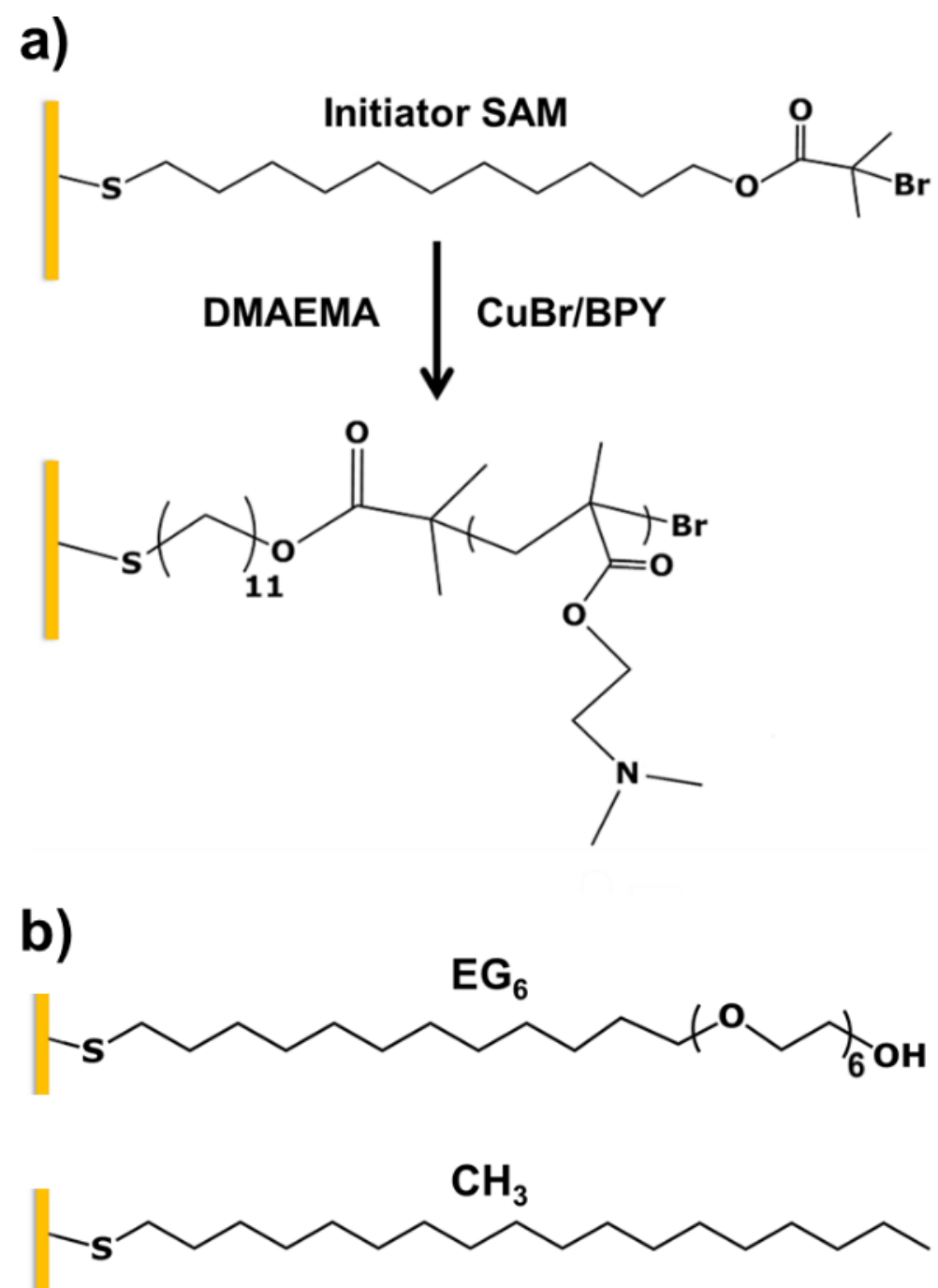

Figure 1. a) Synthesis of cationic PDMAEMA via surface-initiated atom transfer radical polymerization (SI-ATRP). b) Structure of the molecules used for self-assembled monolayers; methyl terminated $\left(\mathrm{CH}_{3}\right)$ and oligo ethylene glycol $\left(\mathrm{EG}_{6}\right)$ terminated. 


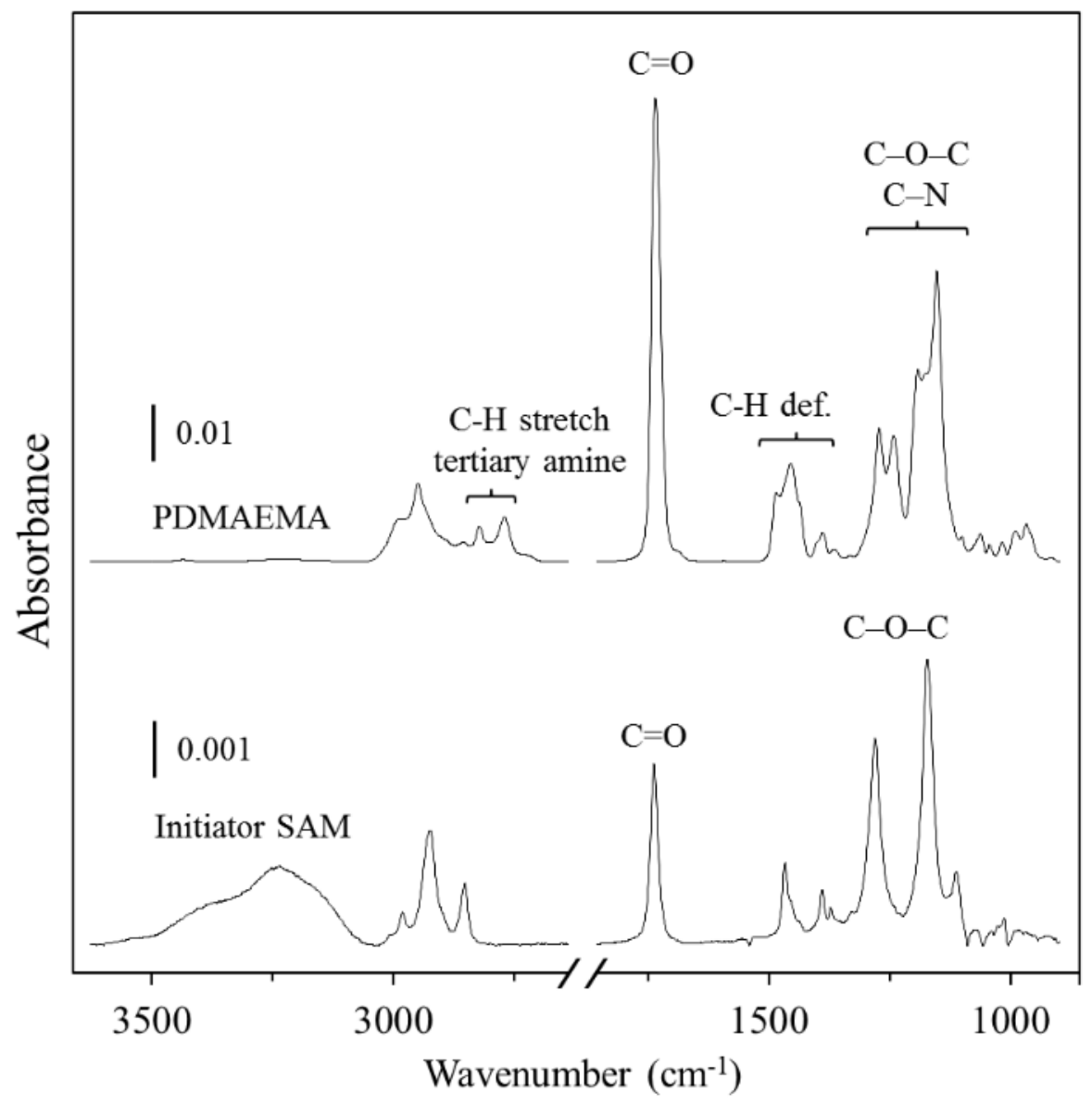

Figure 2. Infrared reflection-absorption spectra of PDMAEMA and the initiator SAM. Note the difference in scale between the two spectra. 
a) Ulva linza

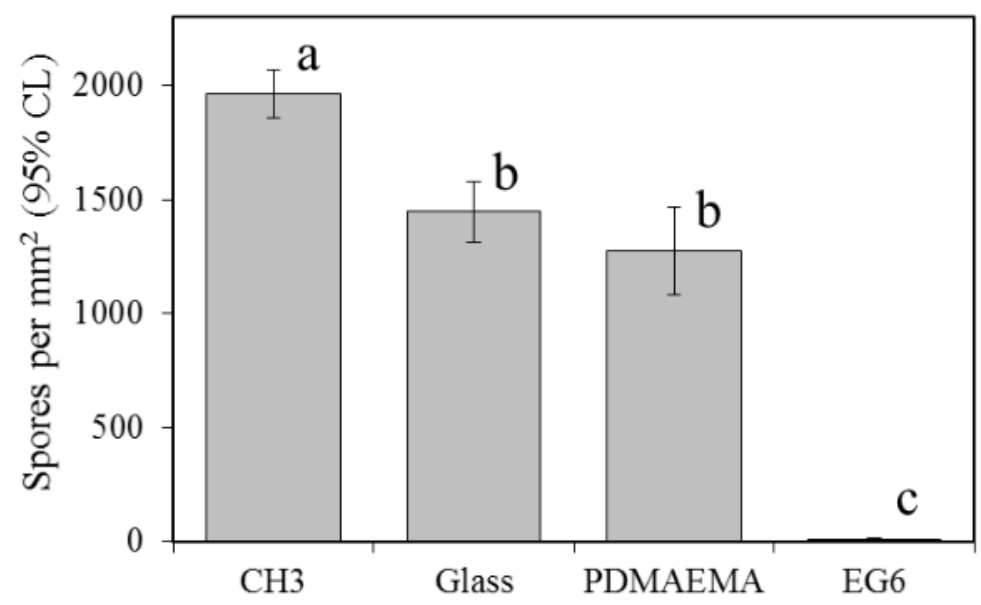

b) Ulva lactuca

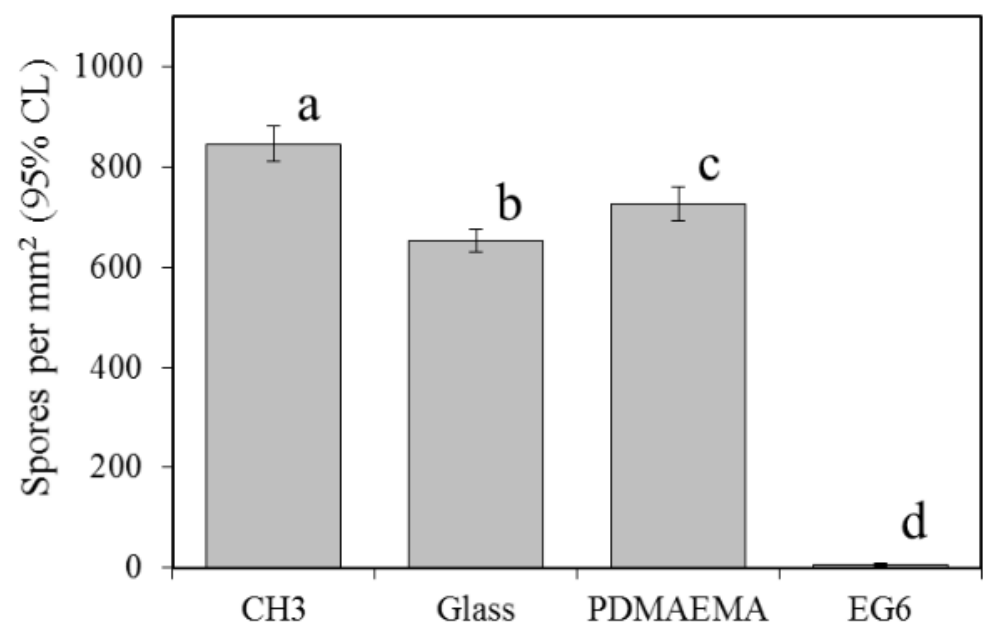

Figure 3. Settlement of a) $U$. linza and b) $U$. lactuca zoospores onto cationic PDMAEMA brushes, hydrophobic $\mathrm{CH}_{3} \mathrm{SAMs}$, glass slides and the $\mathrm{EG}_{6} \mathrm{SAMs}$, obtained from the count of three replicate slides $(n=90)$. Error bars represent $\pm 2 \times$ SE. Similar letters (a-d) indicate data points that do not differ significantly from each other at $p<$ 0.05 . 

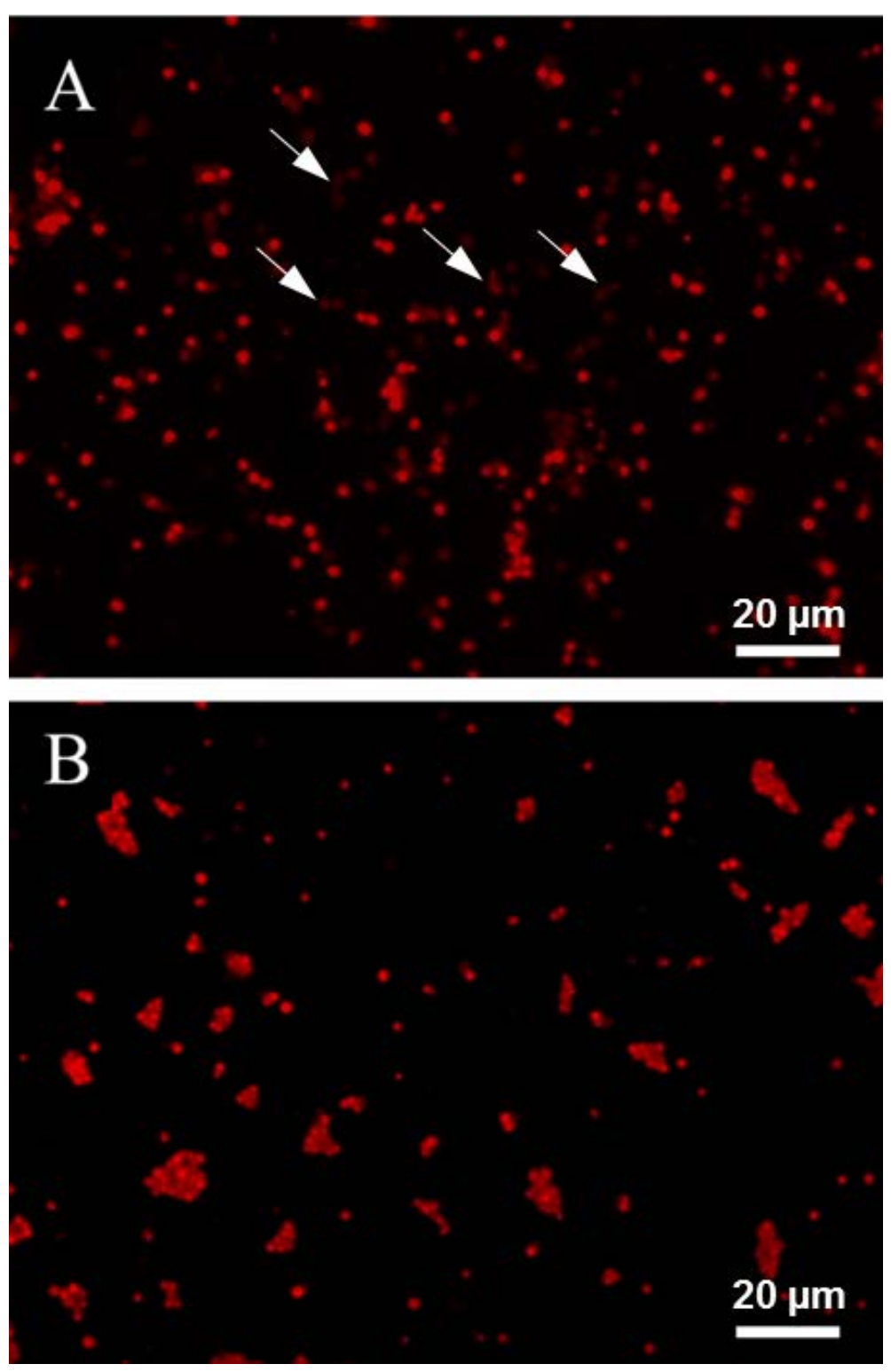

Figure 4. Epifluorescence microscopy images illustrating attached spores of $U$. linza on cationic PDMAEMA (A) and hydrophobic $\mathrm{CH}_{3} \mathrm{SAM}$ (B). Some spores on PDMAEMA have irregular shapes and fluoresce weakly (a few of these are indicated with arrows), in contrast to the spores on the $\mathrm{CH}_{3} \mathrm{SAM}$, which have uniform rounded shape and are brighter. 


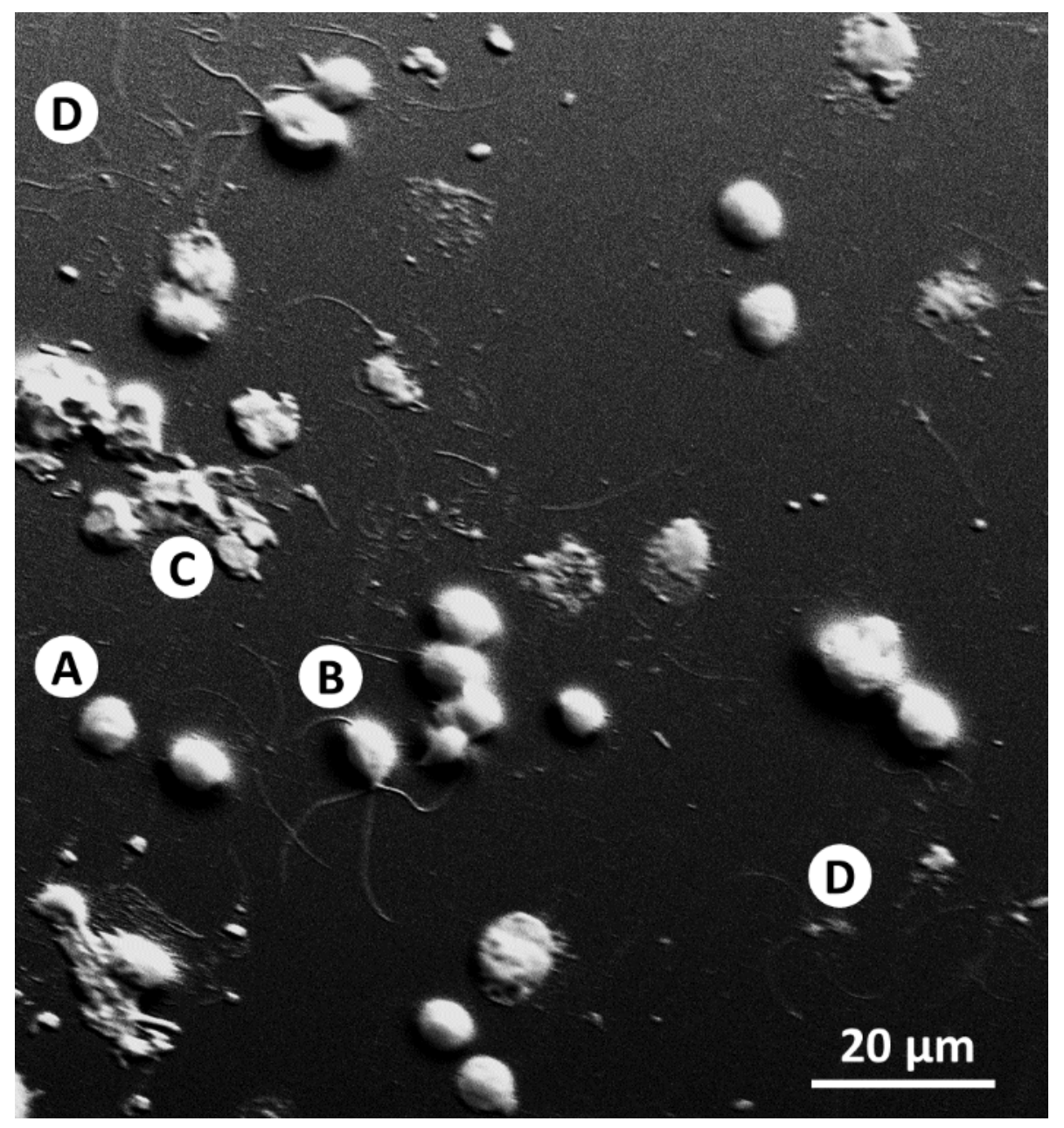

Figure 5. SEM image of $U$. linza spores attached onto the PDMAEMA polymer brush. (A) Normally settled spores have rounded shape and have retracted flagella; (B) pseudosettled spores are pear-shaped, still have flagella and appear to have attached sideon; (C) disrupted spores have irregular shapes; (D) detached flagella from disrupted spores are also present on the surface. 


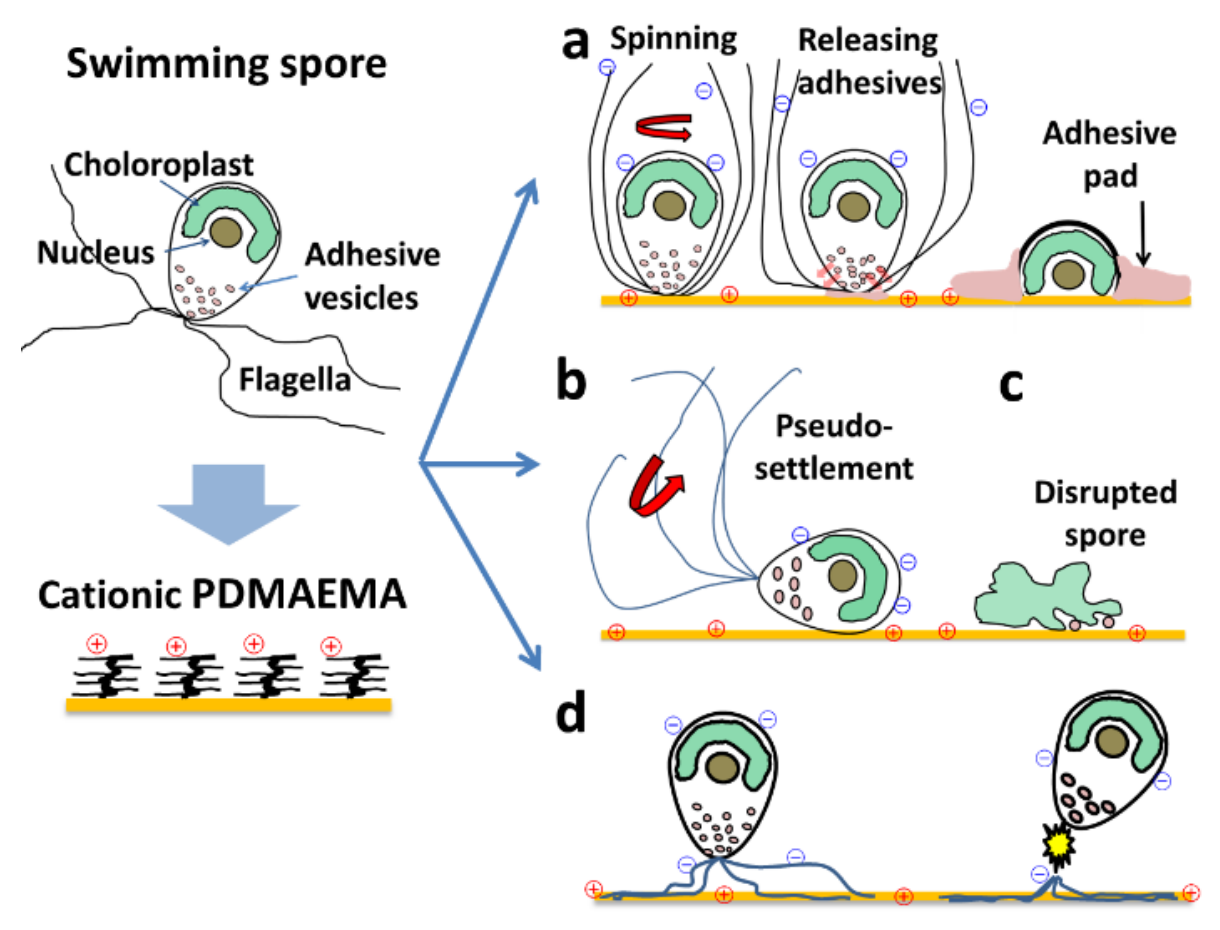

Figure 6. Illustration of the observed types of settlement of spores onto PDMAEMA brushes; (a) normal settlement; (b) side-on pseudosettlement; (c) disrupted spore with irregular shape and with cell contents partially released; (d) flagella entrapment without remaining spore body. 

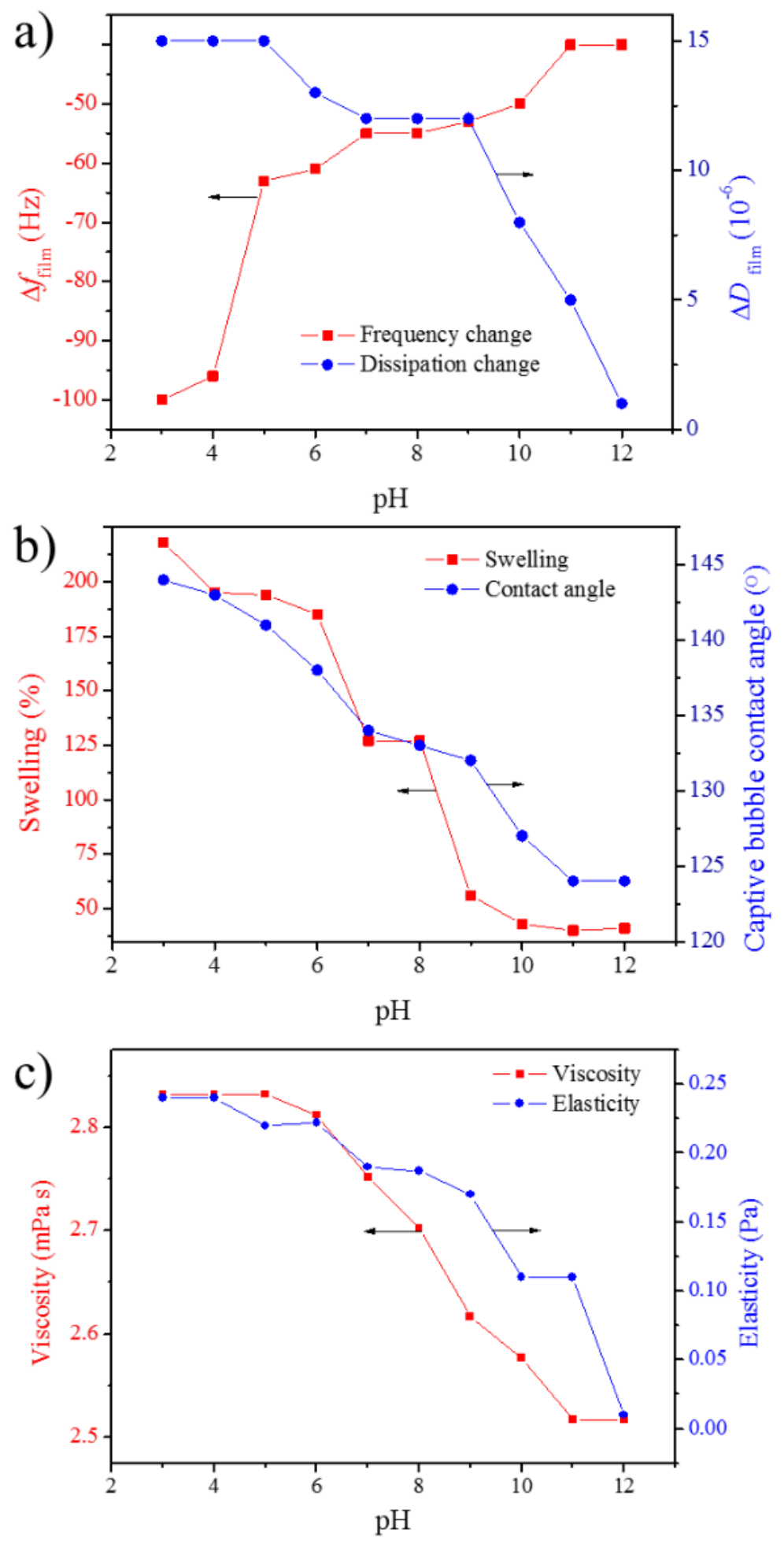


\section{[Cont.]}

Figure 7. (a) Changes in frequency $\left(\Delta f_{\text {film }}\right)$ and dissipation $\left(\Delta D_{\text {film }}\right)$ of a hydrated PDMAEMA film at different $\mathrm{pH}$, as measured by QCM-D, relative to the values obtained on a substrate without the polymer. (b) The data were modelled by a one-layer viscoelastic Voigt model, to yield the swelling at different $\mathrm{pH}$ values, ie the change in thickness relative to the ellipsometric thickness of a PDMAEMA film measured in air. Also in this graph is the captive bubble contact angle, representing the wettability of the hydrated PDMAEMA film in different $\mathrm{pH}$ environments. Arrows indicate the ordinate corresponding to each curve. (c) Viscosity and elasticity of a hydrated PDMAEMA film at different environmental $\mathrm{pH}$ conditions, as obtained by modelling the QCM-D data using a one-layer viscoelastic Voigt model. 
a) Ulva linza

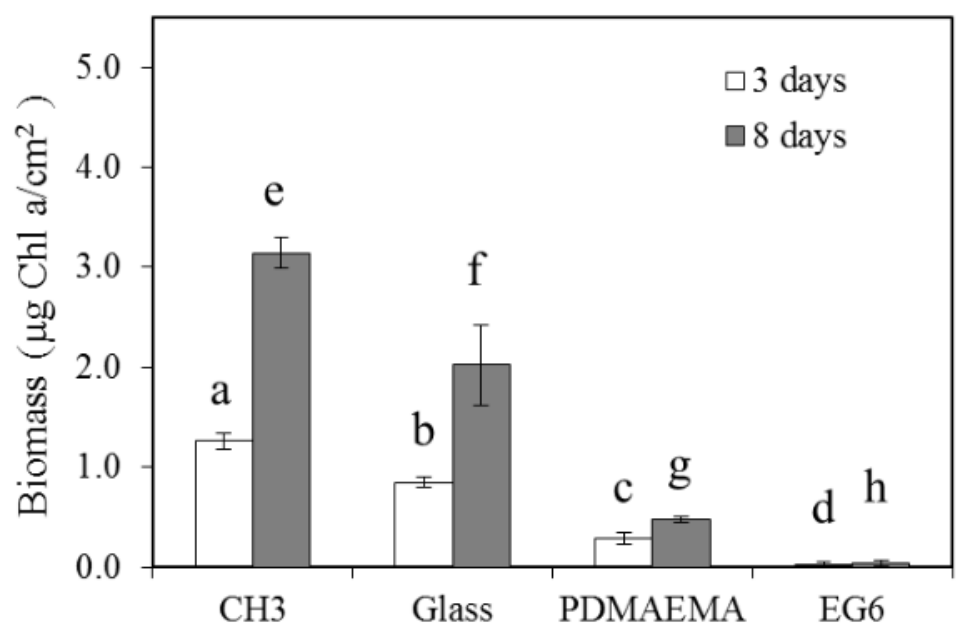

b) Ulva lactuca

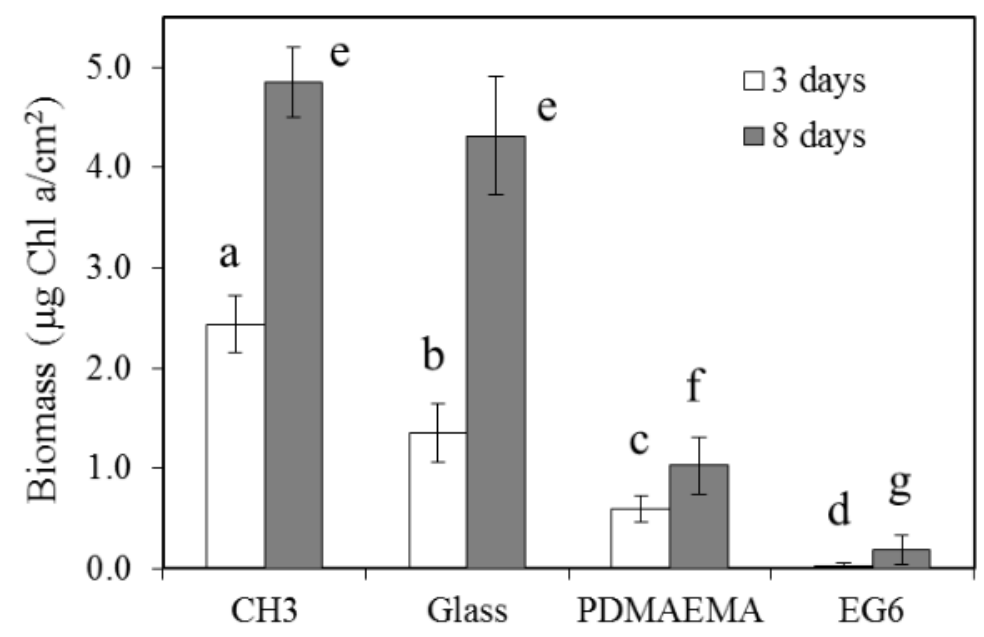

Figure 8. Sporelings biomass of the marine algae $U$. linza (a) and $U$. lactuca (b) on the tested samples, as determined by the chlorophyll $a$ content, and measured after incubation for three and eight days in enriched seawater medium at $23^{\circ} \mathrm{C}$. Error bars represent standard deviation from three measurements. Similar letters indicate data points that do not differ significantly from each other after 3 days (a-d) or after 8 days (e-h), at $\mathrm{p}<0.05$. 


\section{a) Ulva linza}

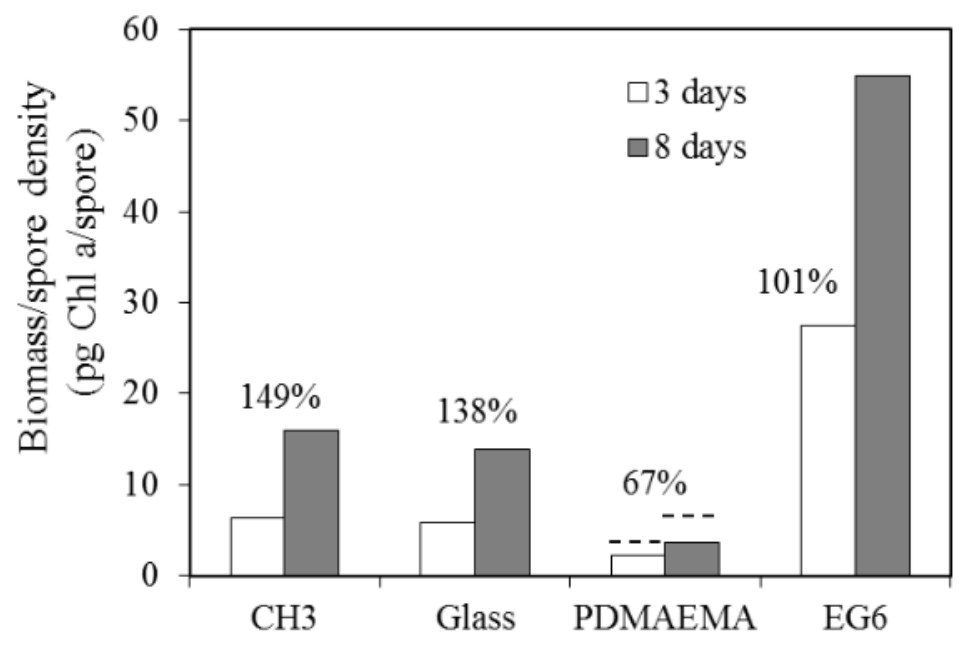

b) Ulva lactuca

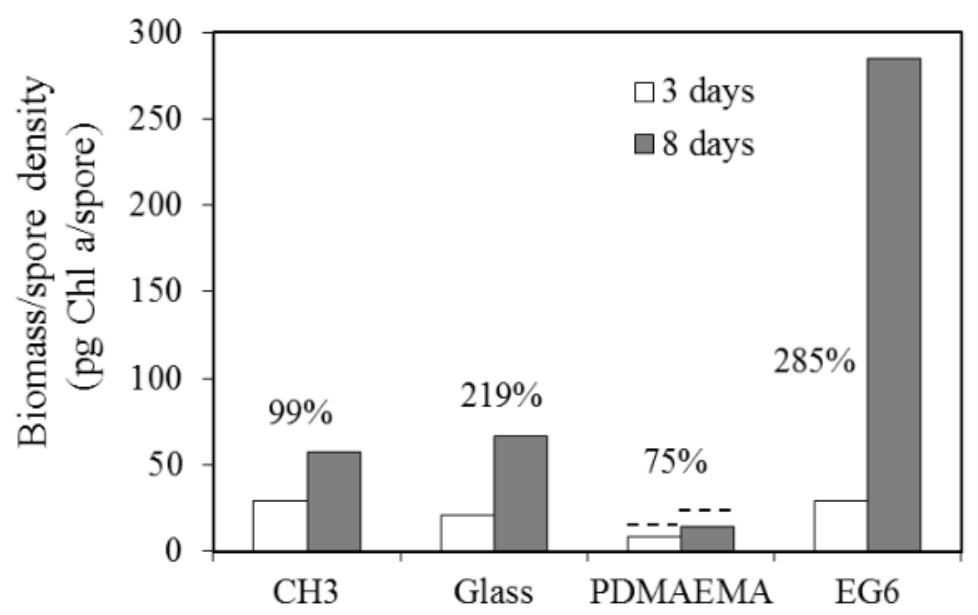

Figure 9. Sporelings biomass (as determined from the chlorophyll $a$ content) scaled by the spore settlement data, giving the average chlorophyll $a$ mass per settled spore, after three and eight days, respectively, for a) $U$. linza and b) $U$. lactuca. Percentages show the increase in biomass from day three to day eight for each sample. The dashed lines above the results for PDMAEMA corresponds to the biomasses obtained if the shown values are divided by $60 \%$, that is, taking into account that only $60 \%$ of the zoospores on the PDMAEMA surfaces were normally settled. 
Table 1. Physicochemical properties of the used surface chemistries, measured in air and in water.

\begin{tabular}{lcccccc}
\hline Sample & $\begin{array}{c}\text { Dry film } \\
\text { thickness } \\
(\AA)\end{array}$ & $\begin{array}{c}\text { Sessile drop } \\
\text { contact angle } \\
\text { in air }\left(^{\circ}\right)\end{array}$ & $\begin{array}{c}\text { Captive bubble } \\
\text { contact angle } \\
\text { in MQ water }\left(^{\circ}\right)\end{array}$ & $\begin{array}{c}\text { Captive bubble } \\
\text { contact angle } \\
\text { in ASW }\left(^{\circ}\right)\end{array}$ & $\begin{array}{c}\text { Captive droplet } \\
\text { contact angle in } \\
n \text {-octane }\left(^{\circ}\right)\end{array}$ & $\begin{array}{c}\text { Surface } \\
\text { free energy } \\
\left(\mathrm{mJ} / \mathrm{m}^{2}\right)\end{array}$ \\
\hline PDMAEMA & $105 \pm 2$ & $74 \pm 2$ & $134 \pm 1$ & $121 \pm 1$ & $121 \pm 1$ & $53 \pm 1$ \\
$\mathrm{CH}_{3}$ SAM & $19 \pm 2$ & $105 \pm 6$ & $58 \pm 2$ & $58 \pm 1$ & $56 \pm 2$ & $28 \pm 1$ \\
$\mathrm{EG}_{6} \mathrm{SAM}$ & $38 \pm 3$ & $50 \pm 1$ & $141 \pm 1$ & $140 \pm 1$ & $134 \pm 2$ & $58 \pm 1$ \\
Glass & - & $48 \pm 2$ & $150 \pm 1$ & $150 \pm 1$ & $152 \pm 1$ & $63 \pm 2$ \\
\hline
\end{tabular}




\section{References}

Bieser AM, Tiller JC. 2011. Mechanistic Considerations on Contact-Active Antimicrobial Surfaces with Controlled Functional Group Densities. Macromol Biosci. 11:526-534.

Bruining MJ, G.T. Blaauwgeers H, Kuijer R, Elisabeth P, Nuijts RMMA, Koole LH. 2000. Biodegradable three-dimensional networks of poly(dimethylamino ethyl methacrylate). Synthesis, characterization and in vitro studies of structural degradation and cytotoxicity. Biomaterials. 21:595-604.

Burillo G, Bucio E, Arenas E, Lopez GP. 2007. Temperature and pH-sensitive swelling behavior of binary DMAEMA/4VP grafts on poly(propylene) films. Macromol Mater Eng. 292:214-219.

Callow JA, Callow ME. 2006. The Ulva Spore Adhesive System. In: Biological Adhesives. Berlin, Heidelberg: Springer Berlin Heidelberg. p. 63-78.

Callow ME, Callow JA, Ista LK, Coleman SE, Nolasco AC, Lopez GP. 2000. Use of self-assembled monolayers of different wettabilities to study surface selection and primary adhesion processes of green algal (Enteromorpha) zoospores. Appl Environ Microb. 66:3249-3254.

Callow ME, Callow JA, Pickett-Heaps JD, Wetherbee R. 1997. Primary adhesion of Enteromorpha (Chlorophyta, Ulvales) propagules: Quantitative settlement studies and video microscopy. J Phycol. 33:938-947.

Callow ME, Callow JE. 2002. Marine biofouling: a sticky problem. Biologist (London). 49:10-14.

Chen Q, Cao X, Liu H, Zhou W, Qin L, An Z. 2013. pH-responsive high internal phase emulsions stabilized by core cross-linked star (CCS) polymers. Polymer Chemistry. 4:4092-4102.

Chen SF, Jiang SY. 2008. A new avenue to nonfouling materials. Adv Mater. 20:335-+.

Cheyne I. 2010. Regulation of Marine Antifouling in International and EC Law. In: Biofouling. Chichester, U.K.: Wiley-Blackwell. p. 306-314.

Dang LX. 1993. Solvation of Ammonium Ion - a Molecular-Dynamics Simulation with Nonadditive Potentials. Chem Phys Lett. 213:541-546.

Ederth T, Nygren P, Pettitt ME, Östblom M, Du C, Broo K, Callow ME, Callow J, Liedberg B. 2008. Anomalous settlement behavior of Ulva linza zoospores on cationic oligopeptide surfaces. Biofouling. 24:303-312.

Ederth T, Pettitt ME, Nygren P, Du CX, Ekblad T, Zhou Y, Falk M, Callow ME, Callow JA, Liedberg B. 2009. Interactions of Zoospores of Ulva linza with Arginine-Rich Oligopeptide Monolayers. Langmuir. 25:9375-9383.

Finlay JA, Callow ME, Ista LK, Lopez GP, Callow JA. 2002. The Influence of Surface Wettability on the Adhesion Strength of Settled Spores of the Green Alga Enteromorpha and the Diatom Amphora. Integr Comp Biol. 42:1116-1122. 
Galvin CJ, Genzer J. 2012. Applications of surface-grafted macromolecules derived from post-polymerization modification reactions. Prog Polym Sci. 37:871-906.

Guo S, Jańczewski D, Zhu X, Quintana R, He T, Neoh KG. 2015. Surface charge control for zwitterionic polymer brushes: Tailoring surface properties to antifouling applications. Journal of Colloid and Interface Science. 452:43-53.

Higaki Y, Kobayashi M, Murakami D, Takahara A. 2016. Anti-fouling behavior of polymer brush immobilized surfaces. Polym J. 48:325-331.

Hilpert K, Elliott M, Jenssen H, Kindrachuk J, Fjell CD, Körner J, Winkler DFH, Weaver LL, Henklein P, Ulrich AS, Chiang SHY, Farmer SW, Pante N, Volkmer R, Hancock REW. 2009. Screening and Characterization of Surface-Tethered Cationic Peptides for Antimicrobial Activity. Chem Biol (Oxford, U K). 16:58-69.

Huang J, Murata H, Koepsel RR, Russell AJ, Matyjaszewski K. 2007. Antibacterial Polypropylene via Surface-Initiated Atom Transfer Radical Polymerization. Biomacromolecules. 8:1396-1399.

Huang JY, Koepsel RR, Murata H, Wu W, Lee SB, Kowalewski T, Russell AJ, Matyjaszewski K. 2008. Nonleaching antibacterial glass surfaces via "Grafting Onto": The effect of the number of quaternary ammonium groups on biocidal activity. Langmuir. 24:6785-6795.

Ilker MF, Nusslein K, Tew GN, Coughlin EB. 2004. Tuning the hemolytic and antibacterial activities of amphiphilic polynorbornene derivatives. J Am Chem Soc. 126:15870-15875.

Jeffrey SW, Humphrey GF. 1975. New Spectrophotometric Equations for Determining Chlorophylls a, B, C1 and C2 in Higher-Plants, Algae and Natural Phytoplankton. Biochem Physiol Pflanz. 167:191-194.

Jia H, Wildes A, Titmuss S. 2012. Structure of pH-Responsive Polymer Brushes Grown at the Gold-Water Interface: Dependence on Grafting Density and Temperature. Macromolecules. 45:305-312.

Jones AL, Harwood JL. 1993. Lipids and lipid metabolism in the marine alga Enteromorpha intestinalis. Phytochemistry. 34:969-972.

Keely S, Rawlinson L-AB, Haddleton DM, Brayden DJ. 2007. A Tertiary AminoContaining Polymethacrylate Polymer Protects Mucus-Covered Intestinal Epithelial Monolayers Against Pathogenic Challenge. Pharmaceutical Research. 25:1193.

Krishnamoorthy M, Hakobyan S, Ramstedt M, Gautrot JE. 2014. Surface-Initiated Polymer Brushes in the Biomedical Field: Applications in Membrane Science, Biosensing, Cell Culture, Regenerative Medicine and Antibacterial Coatings. Chemical Reviews. 114:10976-11026.

Krishnan S, Finlay J, Hexemer A, Wang N, Ober C, Kramer EJ, Callow ME, Callow JA, Fischer D. 2005. Interaction of Ulva and Navicula marine algae with surfaces of pyridinium polymers with fluorinated side-chains. Polym Prepr (Am Chem Soc, Div Polym Chem). 46:1248-1249. 
Kugel AJ, Jarabek LE, Daniels JW, Vander Wal LJ, Ebert SM, Jepperson MJ, Stafslien SJ, Pieper RJ, Webster DC, Bahr J, Chisholm BJ. 2009. Combinatorial materials research applied to the development of new surface coatings XII: Novel, environmentally friendly antimicrobial coatings derived from biocide-functional acrylic polyols and isocyanates. J Coat Technol Res. 6:107-121.

Lee H, Son SH, Sharma R, Won Y-Y. 2011. A Discussion of the pH-Dependent Protonation Behaviors of Poly(2-(dimethylamino)ethyl methacrylate) (PDMAEMA) and Poly(ethylenimine-ran-2-ethyl-2-oxazoline) (P(EI-r-EOz)). J Phys Chem B. 115:844-860.

Lee SB, Koepsel RR, Morley SW, Matyjaszewski K, Sun Y, Russell AJ. 2004a. Permanent, Nonleaching Antibacterial Surfaces. 1. Synthesis by Atom Transfer Radical Polymerization. Biomacromolecules. 5:877-882.

Lee SB, Koepsel RR, Morley SW, Matyjaszewski K, Sun YJ, Russell AJ. 2004b. Permanent, nonleaching antibacterial surfaces. 1. Synthesis by atom transfer radical polymerization. Biomacromolecules. 5:877-882.

Li P, Poon YF, Li WF, Zhu HY, Yeap SH, Cao Y, Qi XB, Zhou CC, Lamrani M, Beuerman RW, Kang ET, Mu YG, Li CM, Chang MW, Leong SSJ, Chan-Park MB. 2011. A polycationic antimicrobial and biocompatible hydrogel with microbe membrane suctioning ability. Nat Mater. 10:149-156.

Liu GM, Wu D, Ma CC, Zhang GZ, Wang HF, Yang SH. 2007. Insight into the origin of the thermosensitivity of poly[2-(dimethylamino)ethyl methacrylate].

ChemPhysChem. 8:2254-2259.

Madkour AE, Dabkowski JM, Nüsslein K, Tew GN. 2009. Fast Disinfecting Antimicrobial Surfaces. Langmuir. 25:1060-1067.

Marshall K, Joint I, Callow ME, Callow JA. 2006. Effect of Marine Bacterial Isolates on the Growth and Morphology of Axenic Plantlets of the Green Alga Ulva linza. Microbial Ecology. 52:302-310.

Melo LD, Mamizuka EM, Carmona-Ribeiro AM. 2010. Antimicrobial Particles from Cationic Lipid and Polyelectrolytes. Langmuir. 26:12300-12306.

Michael TS. 2009. Glycoconjugate organization of Enteromorpha (=Ulva) Flexuosa and Ulva Fasciata (Chlorophyta) zoospores. J Phycol. 45:660-677.

Muñoz-Bonilla A, Fernández-García M. 2012. Polymeric materials with antimicrobial activity. Prog Polym Sci. 37:281-339.

Murata H, Koepsel RR, Matyjaszewski K, Russell AJ. 2007. Permanent, non-leaching antibacterial surfaces-2: How high density cationic surfaces kill bacterial cells. Biomaterials. 28:4870-4879.

Northcote DH, Goulding KJ, Horne RW. 1958. The chemical composition and structure of the cell wall of $<\mathrm{em}>$ Chlorella pyrenoidosa $</ \mathrm{em}>$. Biochemical Journal. 70:391397.

Owens DK, Wendt RC. 1969. Estimation of the surface free energy of polymers. J Appl Polym Sci. 13:1741-1747. 
Park D, Finlay JA, Ward RJ, Weinman CJ, Krishnan S, Paik M, Sohn KE, Callow ME, Callow JA, Handlin DL, Willis CL, Fischer DA, Angert ER, Kramer EJ, Ober CK. 2010. Antimicrobial Behavior of Semifluorinated-Quaternized Triblock Copolymers against Airborne and Marine Microorganisms. ACS Appl Mater Interfaces. 2:703-711.

Pettitt ME, Henry SL, Callow ME, Callow JA, Clare AS. 2004. Activity of commercial enzymes on settlement and adhesion of cypris larvae of the barnacle Balanus amphitrite, spores of the green alga Ulva linza, and the diatom Navicula perminuta. Biofouling. 20:299-311.

Plunkett MA, Wang Z, Rutland MW, Johannsmann D. 2003. Adsorption of pNIPAM Layers on Hydrophobic Gold Surfaces, Measured in Situ by QCM and SPR. Langmuir. 19:6837-6844.

Pranantyo D, Xu LQ, Neoh K-G, Kang E-T, Ng YX, Teo SL-M. 2015. Tea StainsInspired Initiator Primer for Surface Grafting of Antifouling and Antimicrobial Polymer Brush Coatings. Biomacromolecules. 16:723-732.

Rawlinson LAB, Ryan SM, Mantovani G, Syrett JA, Haddleton DM, Brayden DJ. 2010. Antibacterial Effects of Poly(2-(dimethylamino ethyl)methacrylate) against Selected Gram-Positive and Gram-Negative Bacteria. Biomacromolecules. 11:443453.

Rosenhahn A, Finlay JA, Pettit ME, Ward A, Wirges W, Gerhard R, Callow ME, Grunze M, Callow JA. 2009. Zeta potential of motile spores of the green alga Ulva linza and the influence of electrostatic interactions on spore settlement and adhesion strength. Biointerphases. 4:7-11.

Roudman AR, DiGiano FA. 2000. Surface energy of experimental and commercial nanofiltration membranes: Effects of wetting and natural organic matter fouling. J Membrane Sci. 175:61-73.

Roy D, Knapp JS, Guthrie JT, Perrier S. 2008. Antibacterial Cellulose Fiber via RAFT Surface Graft Polymerization. Biomacromolecules. 9:91-99.

Schilp S, Kueller A, Rosenhahn A, Grunze M, Pettitt ME, Callow ME, Callow JA. 2007. Settlement and adhesion of algal cells to hexa(ethylene glycol)-containing selfassembled monolayers with systematically changed wetting properties. Biointerphases. 2:143-150.

Starr RC, Zeikus JA. 1993. Utex - the Culture Collection of Algae at the University-ofTexas at Austin 1993 List of Cultures. J Phycol. 29:1-106.

Subramanyam E, Mohandoss S, Shin H-W. 2009. Synthesis, characterization, and evaluation of antifouling polymers of 4-acryloyloxybenzaldehyde with methyl methacrylate. J Appl Polym Sci. 112:2741-2749.

Thomas KV, Brooks S. 2010. The environmental fate and effects of antifouling paint biocides. Biofouling. 26:73-88.

Tiller JC, Liao CJ, Lewis K, Klibanov AM. 2001. Designing surfaces that kill bacteria on contact. P Natl Acad Sci USA. 98:5981-5985. 
Timofeeva L, Kleshcheva N. 2011. Antimicrobial polymers: mechanism of action, factors of activity, and applications. Appl Microbiol Biotechnol. 89:475-492.

Tischer M, Pradel G, Ohlsen K, Holzgrabe U. 2012. Quaternary Ammonium Salts and Their Antimicrobial Potential: Targets or Nonspecific Interactions? ChemMedChem. 7:22-31.

Vater SM, Finlay J, Callow ME, Callow JA, Ederth T, Liedberg B, Grunze M, Rosenhahn A. 2015. Holographic microscopy provides new insights into the settlement of zoospores of the green alga Ulva linza on cationic oligopeptide surfaces. Biofouling. 31:229-239.

Yan T, Cao WH, Liu SS, Yang J, Xie EY, He MX, Zhang S. 2012. Ethylacetate extracts from the gorgonian coral Subergorgia reticulata reduce larval settlement of Balanus (=Amphibalanus) reticulatus and Pinctada martensii and spore germination of Ulva linza, U. lactuca and Gracilaria tenuistipitata. J Mar Biol Assoc U K. 92:1349-1355.

Yandi W, Mieszkin S, di Fino A, Martin-Tanchereau P, Callow ME, Callow JA, Tyson L, Clare AS, Liedberg B, Ederth T. 2016. Charged Hydrophilic Polymer Brushes and Their Relevance for Understanding Marine Biofouling. Biofouling. 32:609625.

Yang WJ, Neoh K-G, Kang E-T, Lee SSC, Teo SL-M, Rittschof D. 2012. Functional polymer brushes via surface-initiated atom transfer radical graft polymerization for combating marine biofouling. Biofouling. 28:895-912.

Yang WJ, Neoh K-G, Kang E-T, Teo SL-M, Rittschof D. 2014. Polymer brush coatings for combating marine biofouling. Prog Polym Sci. 39:1017-1042.

Ye Q, Gao T, Wan F, Yu B, Pei X, Zhou F, Xue Q. 2012. Grafting poly(ionic liquid) brushes for anti-bacterial and anti-biofouling applications. Journal of Materials Chemistry. 22:13123-13131. 


\section{Supplemental Material}

for

\section{Antialgal activity of poly(2-(dimethylamino)ethyl methacrylate) (PDMAEMA) brushes against the marine alga Ulva}

Wetra Yandi $^{\mathrm{a},}$, Sophie Mieszkin ${ }^{\mathrm{b}, 1,2}$, Maureen E. Callow ${ }^{\mathrm{b}}$, James A. Callow ${ }^{\mathrm{b}}$, John A. Finlay $^{\mathrm{b}, 3}$, Bo Liedberg ${ }^{\mathrm{a}, \mathrm{c}}$, Thomas Ederth ${ }^{\mathrm{a}, *}$

${ }^{a}$ Division of Molecular Physics, IFM, Linköping University, 58183 Linköping, Sweden ${ }^{b}$ School of Biosciences, University of Birmingham, UK

${ }^{c}$ Centre for Biomimetic Sensor Science, School of Materials Science and Engineering, Nanyang Technological University, Singapore

${ }^{1}$ Present address: UMR 1136 Interactions Arbres/Microorganismes, Université de Lorraine, Vandoeuvre-lès-Nancy, France

${ }^{2}$ Present address: UMR 1136 Interactions Arbres/Microorganismes, Laboratoire d'Excellence ARBRE, Institut National de la Recherche Agronomique, INRA-Nancy, Champenoux, France

${ }^{3}$ Present address: School of Marine Science and Technology, Newcastle University, Newcastle NE1 7RU, UK

*Author to whom correspondence should be addressed E-mail: ted@ifm.liu.se 


\section{Stability of the PDMAEMA coatings.}

The stability of the PDMAEMA coatings were tested by prolonged immersion in Milli-Q (MQ) water and filtered artificial seawater (ASW), and monitoring by FT-IRAS. The samples were made with thicker polymer layers than used in the assays, to improve the signal-to-noise ratio, and allow for more accurate monitoring of small structural changes. After polymerization, samples were immersed in MQ water overnight (ca. $20 \mathrm{~h}$ ) to leach out catalyst and unreacted monomers, then rinsed with MQ water, dried and investigated by IRAS. Thereafter, the samples were placed in either MQ water or ASW and left in the dark at room temperature. The samples were rinsed with MQ water, dried, and investigated by IRAS again after 1, 7 and 14 days (only spectra of the pristine, and after 1 and 14 days' immersion are shown in Figure S1). After each investigation, they were rinsed again with MQ water and returned into the respective solution.

For the sample stored in MQ water, the variations in the total integrated area over the range $3100-900 \mathrm{~cm}^{-1}$ is within $\pm 1 \%$ of the value for the pristine surface for all measurements (see Figure S1). For the sample stored in ASW, the corresponding integrated area is reduced by $4 \%$ after 1 day, accompanied by notable redistribution of intensities in the $\mathrm{C}-\mathrm{H}$-stretch region, the emergence of a weak shoulder at $1650 \mathrm{~cm}^{-1}$ near the carbonyl absorption, and an increase in intensities in the range $1100-960 \mathrm{~cm}^{-1}$, and slight reductions in peak intensities for the carbonyl, the higher-frequency $\mathrm{C}-\mathrm{H}$ deformation bands, and the C-O-C and C-N modes between 1300 and $1150 \mathrm{~cm}^{-1}$. After 14 days, the total integrated area has decreased with about 5\% from that of the pristine sample, and spectra obtained after 1 and 14 days are very similar. The sudden decrease and redistribution of intensity after one day, and the negligible change upon further storage over 14 days, along with the absence of changes in MQ water, points to a change in the organization in the polymer due to interactions with ions in the ASW, rather than degradation of the polymer, as the reason for the observed changes. Further, both the surface selection rule and the fact that absorption strengths of vibrational modes may change (resulting in both increases and decreases) as the interactions and conformations in the polymer change, prohibits a direct translation of the change in total integrated intensity, into a change in the amount of polymer. Overall, the observed changes are small, and we conclude that PDMAEMA is stable for the assays presented in this 
manuscript. This is also consistent with literature data, supporting the stability of PDMAEMA over a wide $\mathrm{pH}$ range ${ }^{1,2}$, whereas the structurally similar PDMAEA (poly(2-dimethylaminoethyl acrylate) is prone to self-catalyzed hydrolysis into poly(acrylic acid). ${ }^{3}$

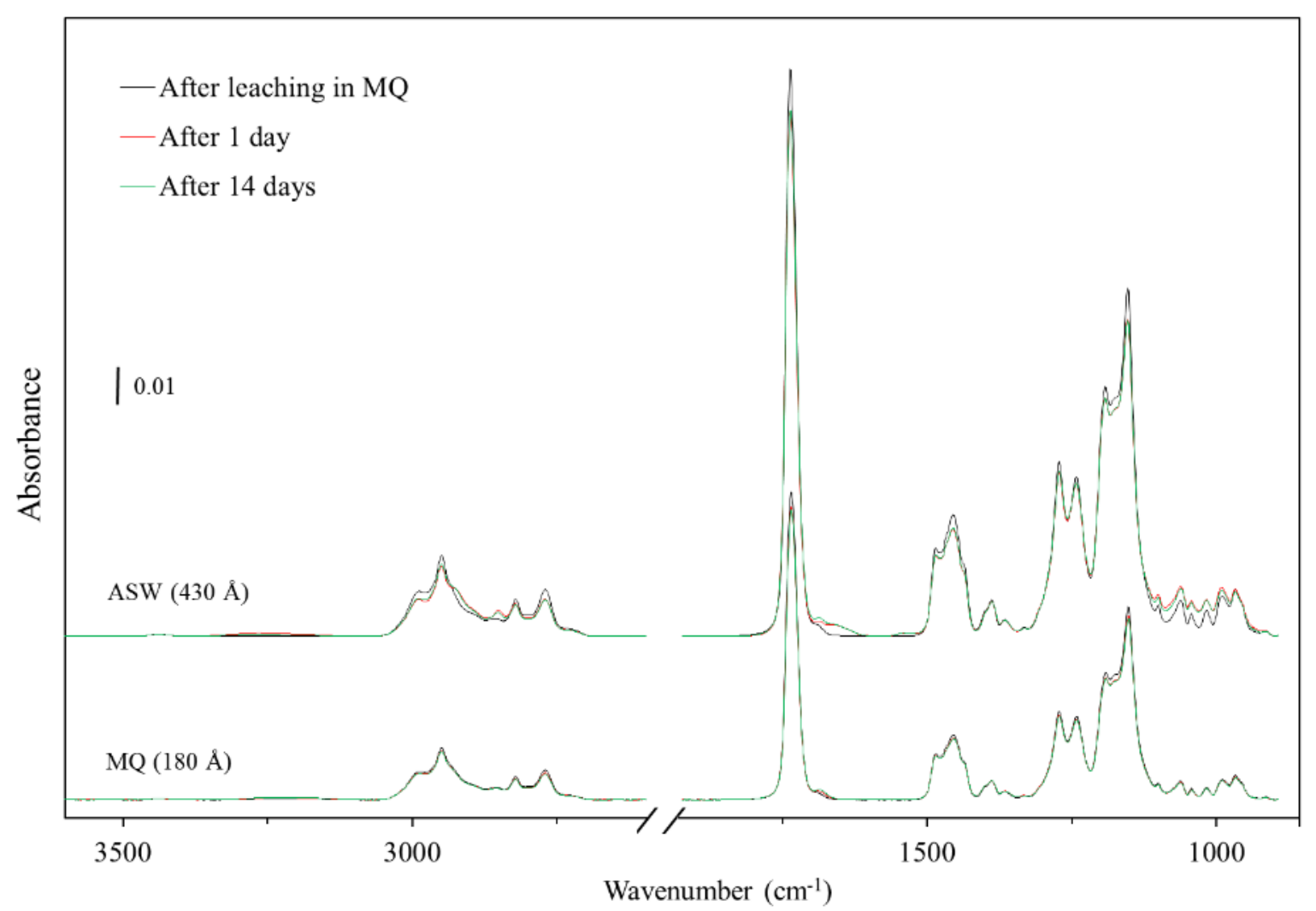

Figure S1. FT-IRAS spectra of PDMAEMA immersed in ASW (top) and MQ water (bottom), for pristine samples, and after 1 and 14 days of immersion, respectively. The thickness of the samples are indicated in parenthesis. 


\section{XPS analysis of the PDMAEMA layers}

The ATRP-prepared PDMEAMA films were tested for residual ions after overnight leaching in MQ water, i.e. the standard leaching procedure employed before use. Since copper ions are biocidal, remaining copper ions from the ATRP synthesis could potentially distort the algal assays. However, the cationic copper ions are easily rinsed away from the cationic polymer, as is confirmed by XPS data, which upon closer analysis, do not show any indication of residual copper in the regions where Cu2p peaks are expected, at 930-960 eV (Figure S2). There are also no peaks that can be associated with bromide, but there seem to be traces of chlorine ions in the film, as evidenced by peaks of very low intenstity at $198 \mathrm{eV}(\mathrm{Cl} 2 \mathrm{p})$ and $269 \mathrm{eV}(\mathrm{Cl} 2 \mathrm{~s})$. Beside this, the spectrum is in good agreement with previously published spectra of PDMAEMA brushes. $^{4}$

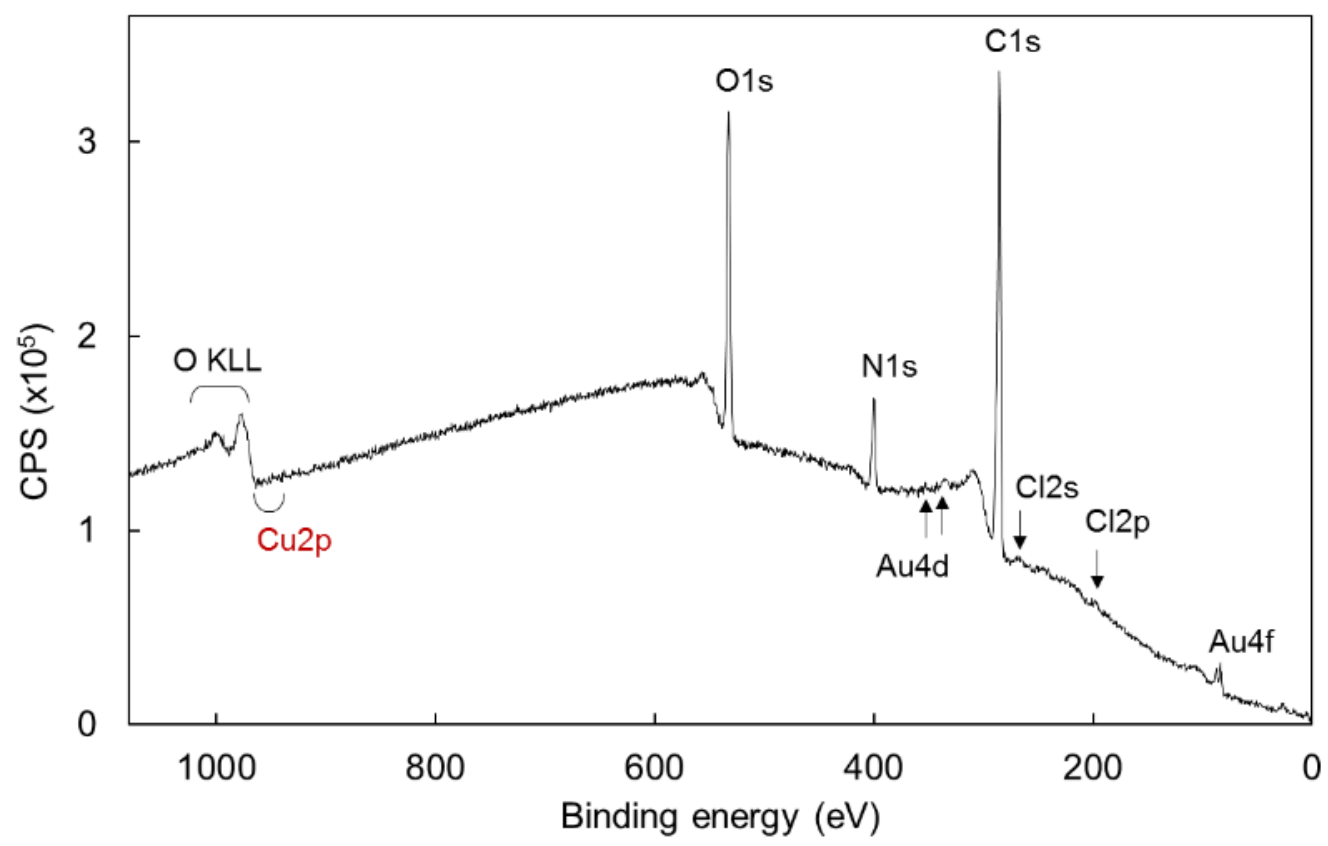

Figure S2. XPS survey spectrum of the PDMAEMA brushes (spectrum kindly provided by Dr Susann Schmidt). 


\section{References}

1. Funhoff, A. M.; van Nostrum, C. F.; Janssen, A. P. C. A.; Fens, M. H. A. M.; Crommelin, D. J. A.; Hennink, W. E. Polymer Side-Chain Degradation as a Tool to Control the Destabilization of Polyplexes. Pharmaceutical Research 2004, 21 (1), 170-176.

2. van de Wetering, P.; Zuidam, N. J.; van Steenbergen, M. J.; van der Houwen, O. A. G. J.; Underberg, W. J. M.; Hennink, W. E. A Mechanistic Study of the Hydrolytic Stability of Poly(2-(dimethylamino)ethyl methacrylate). Macromolecules 1998, 31 (23), 8063-8068.

3. Truong, N. P.; Jia, Z.; Burges, M.; McMillan, N. A. J.; Monteiro, M. J. Self-Catalyzed Degradation of Linear Cationic Poly(2-dimethylaminoethyl acrylate) in Water. Biomacromolecules 2011, 12 (5), 1876-1882.

4. Gupta, S.; Agrawal, M.; Conrad, M.; Hutter, N. A.; Olk, P.; Simon, F.; Eng, L. M.; Stamm, M.; Jordan, R. Poly(2-(dimethylamino)ethyl methacrylate) Brushes with Incorporated Nanoparticles as a SERS Active Sensing Layer. Advanced Functional Materials 2010, 20 (11), 1756-1761. 